\title{
The in vitro and in vivo effects of constitutive light expression on a bioluminescent strain of the mouse enteropathogen Citrobacter rodentium.
}

Hannah M Read, Grant Mills, Sarah Johnson, Peter Tsai, James Dalton, Lars Barquist, Cristin G Print, Wayne M Patrick, Siouxsie Wiles

Bioluminescent reporter genes, such as those from fireflies and bacteria, let researchers use light production as a non-invasive and non-destructive surrogate measure of microbial numbers in a wide variety of environments. As bioluminescence needs microbial metabolites, tagging microorganisms with luciferases means only live metabolically active cells are detected. Despite the wide use of bioluminescent reporter genes, very little is known about the impact of continuous (also called constitutive) light expression on tagged bacteria. We have previously made a bioluminescent strain of Citrobacter rodentium, a bacterium which infects laboratory mice in a similar way to how enteropathogenic Escherichia coli (EPEC) and enterohaemorrhagic E. coli (EHEC) infect humans. In this study, we compared the growth of the bioluminescent $C$. rodentium strain ICC180 with its nonbioluminescent parent (strain ICC169) in a wide variety of environments. To understand more about the metabolic burden of expressing light, we also compared the growth profiles of the two strains under approximately 2000 different conditions. We found that constitutive light expression in ICC180 was near-neutral in almost every non-toxic environment tested. However, we also found that the non-bioluminescent parent strain has a competitive advantage over ICC180 during infection of adult mice, although this was not enough for ICC180 to be completely outcompeted. In conclusion, our data suggest that constitutive light expression is not metabolically costly to $C$. rodentium and supports the view that bioluminescent versions of microbes can be used as a substitute for their nonbioluminescent parents to study bacterial behaviour in a wide variety of environments. 
1 The in vitro and in vivo effects of constitutive light expression on a bioluminescent strain of the mouse enteropathogen Citrobacter rodentium.

3 Read H, ${ }^{1,2}$ Mills G, ${ }^{1,2}$ Johnson S, ${ }^{1,2}$ Tsai $P,{ }^{3}$ Dalton J, ${ }^{1,2,4}$ Barquist L, ${ }^{5}$ Print $\mathrm{C},{ }^{2,3,4}$ Patrick WM, ${ }^{4,6}$

4 Wiles S. $\cdot^{1,2,4^{*}}$

5

6 'Bioluminescent Superbugs Lab, ${ }^{2}$ Department of Molecular Medicine and Pathology, University 7 of Auckland, Auckland, New Zealand; ${ }^{3 B}$ Bioinformatics Institute, School of Biological Sciences,

8 University of Auckland, New Zealand; " Maurice Wilkins Centre for Molecular Biodiscovery, New

9 Zealand; ${ }^{5}$ Institute for Molecular Infection Biology, University of Würzburg, Würzburg, Germany; $10{ }^{6}$ Department of Biochemistry, University of Otago, Dunedin, New Zealand.

${ }^{*}$ Corresponding author: Dr. S Wiles

Mailing address: Dept. Molecular Medicine and Pathology, University of Auckland, Private Bag 92019, Auckland, New Zealand.

Tel: +64 93737599 Extension 84284

Fax: +6493738784

17 E-mail: s.wiles@auckland.ac.nz

Running title: Bioluminescent Citrobacter rodentium: the minimal price of light.

Key words: Citrobacter rodentium; EPEC; EHEC; bioluminescence; lux; luciferase; fitness costs; mouse model; biophotonic imaging; phenotypic microarray. 


\section{Abstract}

25 Bioluminescent reporter genes, such as those from fireflies and bacteria, let researchers use 26 light production as a non-invasive and non-destructive surrogate measure of microbial numbers 27 in a wide variety of environments. As bioluminescence needs microbial metabolites, tagging microorganisms with luciferases means only live metabolically active cells are detected. Despite the wide use of bioluminescent reporter genes, very little is known about the impact of continuous (also called constitutive) light expression on tagged bacteria. We have previously made a bioluminescent strain of Citrobacter rodentium, a bacterium which infects laboratory mice in a similar way to how enteropathogenic Escherichia coli (EPEC) and enterohaemorrhagic E. coli (EHEC) infect humans. In this study, we compared the growth of the bioluminescent $C$.

34 rodentium strain ICC180 with its non-bioluminescent parent (strain ICC169) in a wide variety of environments. To understand more about the metabolic burden of expressing light, we also compared the growth profiles of the two strains under approximately 2000 different conditions.

37 We found that constitutive light expression in ICC180 was near-neutral in almost every non-toxic 38 environment tested. However, we also found that the non-bioluminescent parent strain has a 39 competitive advantage over ICC180 during infection of adult mice, although this was not enough 40 for ICC180 to be completely outcompeted. In conclusion, our data suggest that constitutive light 41 expression is not metabolically costly to $C$. rodentium and supports the view that bioluminescent 42 versions of microbes can be used as a substitute for their non-bioluminescent parents to study 43 bacterial behaviour in a wide variety of environments. 


\section{Introduction}

45 Bioluminescence is the by-product of a chemical reaction which has evolved in a wide variety of 46 creatures for different purposes. This 'living light' allows fireflies like Photinus pyralis to find a 47 mate $^{1}$, larvae like the New Zealand glow worm Arachnocampa luminosa to lure prey², and the 48 bacterium Aliivibrio fischeri (formally Vibrio fischeri) to camouflage its nocturnal symbiont, the 49 Hawaiian bobtail squid, while hunting ${ }^{3}$. Bioluminescence is produced by the oxidation of a 50 substrate (a luciferin) by an enzyme (a luciferase), which usually requires energy and oxygen.

51 Cloning of the bioluminescence genes from P. pyralis ${ }^{4}$, V. fischeri ${ }^{5}$ and Photorhabdus

52 luminescens ${ }^{6}$, has let researchers use light production as a real-time non-invasive and non53 destructive surrogate measure of microbial numbers in a wide variety of different culture 54 environments, including within laboratory animals ${ }^{7}$. This has proven particularly useful for 55 studying microorganisms which take several weeks to grow on selective media, such as the 56 bacterium Mycobacterium tuberculosis ${ }^{8,9}$. As bioluminescence requires microbial metabolites, 57 such as ATP and reduced flavin mononucleotide $\left(\mathrm{FMNH}_{2}\right)$, tagging microorganisms with 58 luciferases means only live, metabolically active cells are detected.

60 Of the available bioluminescent reporter systems, the most widely used in bacteriology research 61 is the bacterial luminescence reaction, encoded by the lux gene operon. The reaction involves 62 the oxidation of a long chain aldehyde and $\mathrm{FMNH}_{2}$, resulting in the production of oxidised flavin 63 (FMN), a long chain fatty acid, and the emission of light at $490 \mathrm{~nm}{ }^{10}$. The reaction is catalysed 64 by bacterial luciferase, a $77 \mathrm{kDa}$ enzyme made up of an alpha and a beta subunit encoded by 65 the IuxA and luxB genes, respectively. The $\operatorname{lux} C, D$ and $E$ genes encode the subunits of a multienzyme complex responsible for regenerating the aldehyde substrate from the fatty acid

67 produced by the reaction. A significant advantage of the bacterial bioluminescence system is 68 the ability to express the biosynthetic enzymes for substrate synthesis, allowing light to be 
69 produced constitutively. One of the underlying motivations for using lux-tagged bacteria is the

70 reduction in the number of animals needed for in vivo experiments, an ethical and legislative

71 requirement in many countries. Using a technique known as biophotonic imaging, tagged

72 bacteria can be non-invasively and non-destructively visualised and quantified on multiple

73 occasions from within the same group of infected animals, whereas culture based techniques

74 need groups of animals to be euthanised at each time point of interest ${ }^{7}$. However, very little is

75 known about the impact of constitutive light expression on tagged bacteria. We hypothesise that

76 light production will impose a metabolic burden on the tagged bacteria, with the actual fitness

77 costs dependent on the host bacterial species, the site of insertion of the bioluminescence

78 genes and their expression levels.

79

80 We have previously made a lux-tagged derivative of Citrobacter rodentium ${ }^{11}$, a bacterium that

81 infects laboratory mice using the same virulence mechanisms as the life-threatening pathogens,

82 enteropathogenic Escherichia coli (EPEC) and enterohaemorrhagic E. coli (EHEC) use to infect

83 humans ${ }^{12,13}$. C. rodentium ICC180 contains a single chromosomally-located copy of the lux

84 operon from P. luminescens, alongside a gene for resistance to the antibiotic kanamycin. We

85 have previously non-invasively tracked ICC180 during infection of mice ${ }^{14}$, demonstrating that $C$.

86 rodentium rapidly spreads between infected and uninfected animals and that bacteria shed from

87 infected mice are 1,000 times more infectious than laboratory grown bacteria ${ }^{15}$. While we have

88 shown that ICC180 can reach similar numbers within the gastro-intestinal tracts of infected mice

89 and causes similar pathology when compared to its non-bioluminescent parent strain ICC16911,

90 we have never fully investigated the impact of constitutive light expression on the fitness of

91 ICC180.

92

93 In this study we set out to determine whether C. rodentium ICC180 has a competitive

94 disadvantage when competed against its non-bioluminescent parent ICC169 in a range of in 
95 vitro and in vivo environments. We also sequenced the genome and associated plasmids of

96 ICC180 to determine whether there were any other genetic differences between the two strains,

97 perhaps as a result of the transposon mutagenesis technique ${ }^{16}$ used to generate ICC180.

98 Finally, we compared the growth profiles of the two strains using the BIOLOG Phenotypic

99 Microarray (PM) system, a rapid 96-well microtitre plate assay for phenotypically profiling

100 microorganisms based on their growth under approximately 2000 different metabolic

101 conditions ${ }^{17}$.

102 


\section{Materials and methods}

104 Bacterial strains and culture conditions. The bacterial strains used in this study were

Citrobacter rodentium ICC169 (spontaneous nalidixic acid resistant mutant) ${ }^{11}$ and ICC180

106 (nalidixic acid and kanamycin resistant) ${ }^{11}$. Bacteria were revived and grown from frozen stocks

107 stored at $-80^{\circ} \mathrm{C}$ in order to prevent adaptation of $C$. rodentium over multiple laboratory

108 subcultures. Bacteria were grown at $37^{\circ} \mathrm{C}$ with shaking at 200 revolutions per minute (RPM) in

109 LB-Lennox media (Fort Richard Laboratories Ltd., Auckland, New Zealand) or in defined

110 minimal media (modified Davis \& Mingioli media ${ }^{18}$ ), containing ammonium sulphate $\left[1 \mathrm{~g} \mathrm{I}^{-1}\right]$,

111 potassium dihydrogen phosphate $\left[4.5 \mathrm{~g} \mathrm{l}^{-1}\right]$, dipotassium hydrogen phosphate anhydrous [10.5

$\left.112 \mathrm{~g} \mathrm{l}^{-1}\right]$, sodium citrate dihydrate $\left[5 \mathrm{~g} \mathrm{l}^{-1}\right]$, magnesium sulfate heptahydrate [24.65 $\left.\mathrm{mg} \mathrm{l}^{-1}\right]$, thiamine

$113\left[0.5 \mathrm{mg} \mathrm{l}^{-1}\right]$, supplemented with $1 \%$ glucose) at $37^{\circ} \mathrm{C}$. Antibiotics (kanamycin $\left[50 \mathrm{ug} \mathrm{ml}^{-1}\right]$,

114 nalidixic acid [50 ug ml $\left.\mathrm{I}^{-1}\right]$ ) were only added to the media if they were required for selection. All

115 chemicals and antibiotics were obtained from Sigma-Aldrich (Australia).

116 Genome sequencing and analysis. Genomic DNA was prepared from bacteria grown

117 overnight in LB-Lennox broth. Whole genome sequencing was performed using the Illumina

118 HiSeq platform by BGI (Hong Kong). A total of 3,414,820 paired-end 90 bp reads were

119 generated for ICC169 and 3,369,194 for ICC180. Data was quality trimmed using

120 DynamicTrim ${ }^{19}$ (minimum Phred score 25) and filtering of reads shorter than 45 bp after quality

121 trimming was performed using LengthSort ${ }^{19}$; both programmes are part of the SolexaQA

122 software package ${ }^{19}$. After filtering, 2,444,336 paired reads were retained for ICC169 and

$1232,383,491$ for ICC 180. All remaining high quality and properly paired reads were mapped to the

124 reference strain C. rodentium ICC168 (Genbank accession number FN543502.120) using the

125 default settings in BWA ${ }^{21}$. On average, $95 \%$ of all high quality reads mapped uniquely to

126 ICC168 (94.8\% for ICC169 and $95.2 \%$ for ICC180) and single nucleotide polymorphisms

127 (SNPs) and indels that were present only in ICC180 at 100\% were identified using Samtools 
128 mpileup ${ }^{22}$. SNPs and indels were confirmed by PCR and sequencing. In addition, the reads 129 were also analysed using BreSeq version $0.24 \mathrm{rc6} 6^{23}$, which identified predicted mutations that 130 were statistically valid. To locate the insertion site of the lux operon and kanamycin resistance $131\left(\mathrm{Km}^{\mathrm{R}}\right)$ gene, we first performed de novo assembly on quality trimmed data for ICC180 using 132 EDENA v3.024. All assembled contigs were mapped to the $C$. rodentium reference strain 133 ICC168 using Geneious ${ }^{25}$ and contigs unmapped to ICC168 were BLAST searched against the 134 Iux operon and $\mathrm{Km}^{\mathrm{R}}$ gene. We located both the lux operon and $\mathrm{Km}^{\mathrm{R}}$ gene on an unmapped 135 contig $117,921 \mathrm{bp}$ long. To identify the position of this contig, we broke the contig into two 136 segments based on the location of lux operon and $\mathrm{Km}^{\mathrm{R}}$ gene positions on the contig, and 137 performed additional reference mapping to ICC168 to identify the insertion site. To determine 138 changes to the plasmids present in C. rodentium, reads were also mapped to the sequenced plasmids pCROD1 (Genbank accession number FN543503.1), pCROD2 (Genbank accession number FN543504.1), pCROD3 (Genbank accession number FN543505.1), and pCRP3

141 (Genbank accession number NC_003114).

142 Phenotypic microarrays. Phenotypic microarrays were performed by BIOLOG Inc. (California, 143 USA) as described previously ${ }^{17}$. Assays were performed in duplicate using plates PM1-20 144 (Supplementary Table 1). The data was exported and analysed in the software package $\mathrm{R}$ as 145 previously described ${ }^{26}$. Briefly, growth curves were transformed into Signal Values (SVs) ${ }^{27}$ 146 summarising the growth over time while correcting for background signal. Principal component 147 analyses showed a clear separation by genotype, suggesting reproducible differences in 148 metabolism between the two strains. A histogram of log signal values displayed a clear bimodal 149 distribution, which we interpreted as representing non-respiring cells ('off', low SV) and respiring 150 cells ('on', high SV), respectively. Normal distributions were fitted to these two distributions 151 using the R MASS package, and these models were then used to compute log-odds ratios for 152 each well describing the probability that each observation originated from the 'on' or 'off' 
153 distribution. Wells which were at least 4 times more likely to come from the 'on' distribution than

154 the 'off' in both replicates were considered to be actively respiring. In order to determine the

155 significance of observed differences between genotypes, we applied the moderated t-test

156 implemented in the limma R/Bioconductor package ${ }^{28}$. Wells with a Benjamini-Hochberg

157 corrected P-value of less than 0.05 , that is allowing for a false discovery rate of $5 \%$, and which

158 were called as actively respiring for at least one genotype, were retained for further analysis.

159 The data was also analysed using the DuctApe software suite ${ }^{29}$. Growth curves were analysed

160 using the dphenome module, with the background signal subtracted from each well. Based on

161 the results of an elbow test (Supplementary Fig.1), 7 clusters were chosen for k-means

162 clustering. An Activity Index (AV) was created based on the clustering, ranging from 0 (minimal

163 activity) to 6 (maximal activity). AV data was visualised using the plot and ring commands of the

164 dphenome module (Supplementary Fig.2).

165 In vitro growth experiments. Briefly, for individual growth curves, $10 \mathrm{ml}$ of either LB-Lennox or defined minimal medium was inoculated with $20 \mu \mathrm{l}$ of a culture grown overnight in LB-Lennox broth. Cultures were grown at $37^{\circ} \mathrm{C}$ with shaking at $200 \mathrm{RPM}$ and samples were removed at regular intervals to measure bioluminescence, using a VICTOR X Light Plate reader (Perkin

169 Elmer), and viable counts, by plating onto LB-Lennox Agar (Fort Richard Laboratories Ltd., 170 Auckland, New Zealand). Overnight cultures were plated to determine the initial inocula.

171 Experiments were performed on seven separate occasions and results used to calculate area

172 under curve (AUC) values for each strain. For the competition experiments, $10 \mu$ of a culture

173 grown overnight in LB-Lennox broth was used to inoculate $1 \mathrm{ml}$ of defined minimal medium, with

174 the mixed culture tubes receiving $5 \mu$ l of each strain. Inoculated tubes were incubated overnight

175 at $37^{\circ} \mathrm{C}$ with shaking at $200 \mathrm{RPM}$, followed by serial dilution in sterile phosphate buffered saline

176 (PBS) for plating onto LB Agar containing either nalidixic acid or kanamycin. The ratio of

177 colonies that grew on media containing each antibiotic was used to determine the proportion of 
178

179

180

181

182

183

184

185

186

187

188

189

190

191

192

193

194

195

196

197

198

199

200

201

each strain remaining. Experiments were performed on eight separate occasions and the results used to calculate AUC values and competitive indices $(\mathrm{Cl})$. Cl's were calculated as follows: $\mathrm{Cl}=$ [strain of interest output/competing strain output]/[strain of interest input/competing strain input] ${ }^{30,31}$.

Infection of Galleria mellonella. $5^{\text {th }}$ instar Galleria mellonella larvae (waxworms) were obtained from a commercial supplier (Biosuppliers.com, Auckland, New Zealand). Bacteria were grown overnight in LB-Lennox broth and used to infect waxworms which were pale in colour and weighed approximately 100-200 mg. Waxworms were injected into one of the last set of prolegs with $20 \mu \mathrm{l}$ of approximately $10^{8}$ colony forming units (CFU) of bacteria using a $1 \mathrm{ml}$ fine needle insulin syringe. Waxworms were injected with either ICC169, ICC180 or a 1:1 mix and incubated at $37^{\circ} \mathrm{C}$. Throughout the course of a $24 \mathrm{~h}$ infection, individual waxworms were inspected for phenotypic changes and scored using a standardised method for assessing waxworm health (the Caterpillar Health Index [CHI]) which we have developed. Briefly, waxworms were monitored for movement, cocoon formation, melanisation, and survival. Together, these data form a numerical scale, with lower $\mathrm{CHI}$ scores corresponding with more serious infections and higher scores with healthier waxworms. Scores were used to calculate AUC values.

Bioluminescence (given as relative light units $[R L U]$ ) was measured at regular intervals from waxworms infected with ICC180 (Supplementary Fig.3). Waxworms were placed into individual wells of a dark OptiPlate-96 well microtitre plate (Perkin Elmer) and bioluminescence measured for 1 second to provide relative light units $(R L U)$ /second using the VICTOR X Light Plate reader. Waxworms infected with ICC169 were used as a control. Following death, or at $24 \mathrm{~h}$, waxworms were homogenised in PBS and plated onto LB-Lennox Agar containing the appropriate antibiotics. Independent experiments were performed three times using 10 waxworms per group. 
202 Infection of Mice. Female 6-7 week old C57BL/6Elite mice were provided by the Vernon 203 Jansen Unit (University of Auckland) from specific-pathogen free (SPF) stocks. All animals were 204 housed in individually HEPA-filtered cages with sterile bedding and free access to sterilised food 205 water. Experiments were performed in accordance with the New Zealand Animal Welfare Act 206 (1999) and institutional guidelines provided by the University of Auckland Animal Ethics

207 Committee, which reviewed and approved these experiments under applications R1003 and 208 R1496. Bacteria grown overnight in LB-Lennox broth were spun at 4500 RPM for 5 minutes, 209 and resuspended in a tenth of the volume of sterile PBS, producing a 10x concentrated 210 inoculum. Animals were orally inoculated using a gavage needles with $200 \mu$ of either ICC169, 211 ICC 180, or a 1:1 mix (containing approximately $10^{8} \mathrm{CFU}$ of bacteria) and biophotonic imaging 212 used to determine correct delivery of bacteria to the stomach. The number of viable bacteria 213 used as an inoculum was determined by retrospective plating onto LB-Lennox Agar containing 214 either nalidixic acid or kanamycin. Stool samples were recovered aseptically at various time 215 points after inoculation, and the number of viable bacteria per gram of stool was determined 216 after homogenisation at $0.1 \mathrm{~g} \mathrm{ml}^{-1}$ in PBS and plating onto LB-Lennox Agar containing the 217 appropriate antibiotics. The number and ratio of colonies growing on each antibiotic was used to 218 calculate AUC values and Cl's as described above. Independent experiments were performed 219 twice using 6 animals per group.

In vivo bioluminescence imaging. Biophotonic imaging was used to noninvasively measure the bioluminescent signal emitted by $C$. rodentium ICC180 from anaesthetised mice to provide 222 information regarding the localisation of the bacterium. Prior to being imaged, the abdominal 223 area of each mouse was shaved, using a Vidal Sasoon handheld facial hair trimmer, to minimise any potential signal impedance by melanin within pigmented skin and fur. Mice were 225 anaesthetised with gaseous isoflurane and bioluminescence (given as photons second-1 $\mathrm{cm}^{-2}$ steradian $[s r]^{-1}$ ) was measured using the $\mathrm{IVIS}^{\circledR}$ Kinetic camera system (Perkin Elmer). A 
227 photograph (reference image) was taken under low illumination before quantification of photons 228 emitted from ICC180 at a binning of four over 1 minute using the Living Image software (Perkin 229 Elmer). The sample shelf was set to position D (field of view, $12.5 \mathrm{~cm}$ ). For anatomic 230 localisation, a pseudocolor image representing light intensity (blue, least intense to red, most 231 intense) was generated using the Living Image software and superimposed over the gray-scale 232 reference image. Bioluminescence in specific regions of individual mice also was quantified 233 using the region of interest tool in the Living Image software program (given as photons second$234{ }^{1}$ ) and used to calculate AUC values for each individual animal.

235 Statistical analyses. Data was analysed using GraphPad Prism 6. Data was tested for 236 normality using the D'Agostino-Pearson test; data which failed normality was analysed using a 237 non-parametric test, while data which passed normality was analysed using a parametric test. 238 One-tailed tests were used to test the hypothesis that constitutively expressing light gives 239 ICC180 a differential fitness cost compared to the non-bioluminescent parent strain ICC169. 240 When comparing multiple experimental groups, Dunn's post hoc multiple comparison test was 241 applied. 


\section{Results}

245 Bioluminescent Citrobacter rodentium strain ICC180 has three altered chromosomal 246 genes and a large deletion in plasmid pCROD1 in addition to insertion of the lux operon 247 and kanamycin resistance gene.

248 We determined the whole genome draft sequences of C. rodentium ICC169 and ICC180 using 249 Illumina sequence data. Compared with sequenced type strain ICC168 (Genbank accession 250 number FN543502.1), both strains have a substitution of a guanine (G) to an adenine (A) 251 residue at $2,475,894 \mathrm{bp}$, resulting in an amino acid change from serine (Ser) to phenylalanine 252 (Phe) within gyrA, the DNA gyrase subunit, and conferring resistance to nalidixic acid. The 253 sequencing data indicate that the lux operon and kanamycin resistance gene (a 7,759 bp 254 fragment) has inserted at 5,212,273 bp, disrupting the coding region of a putative site-specific 255 DNA recombinase (Figure 1). In addition to the presence of the lux operon and kanamycin 256 resistance gene, we found that the genome of ICC180 differs from ICC169 by two single nucleotide polymorphisms (SNPs), a single base pair insertion (of a G residue at 3,326,092 bp which results in a frameshift mutation within $R O D \_31611$, a putative membrane transporter) and described for C. rodentium were present in ICC180, however the largest of these plasmids, pCROD1, shows evidence of extensive deletion events and is missing 41 out of 60 genes

262 (Supplementary Table 2).

263

Constitutive light expression does not greatly impact the metabolism of $C$. rodentium 265 ICC180.

C. rodentium ICC169 and its bioluminescent derivative ICC180 were grown on two separate occasions using PM plates 1-20. We analysed the data using the DuctApe software suite which calculates an activity index (AV) for each strain in response to each well (Supplementary Fig.2).

269 Next, the growth curve data were transformed into Signal Values (SVs) as previously 
270 described ${ }^{26}$, summarising the growth of each strain over time for each well. Wells which were

271 considered to be actively respiring were analysed using the moderated t-test implemented in the

272 limma R/Bioconductor package ${ }^{28}$. Those wells with a Benjamini-Hochberg corrected P-value of

273 less than 0.05 are shown in Table 2 (with corresponding growth curves in Supplementary Fig.

274 3). Our results indicate that the growth of the two strains significantly differed $(p=<0.05)$ in

$27526 / 1,920$ wells. Of these $>80 \%$ are from the PM11-20 plates, which belong to the chemical

276 category, suggesting that the expression of bioluminescence is near-neutral in almost every

277 non-toxic environment. The bioluminescent strain ICC180 is able to use D-glucosamine, cytidine

278 and Ala-His as nitrogen sources, and inositol hexaphosphate as a phosphate source, and grew

279 significantly better than ICC169 in the presence of 11 chemicals: the antibiotics kanamycin,

280 paromomycin, geneticin, spiramycin, rolitetracycline, doxycycline, cefoxitin; the quaternary

281 ammonium salt dequalinium chloride; coumarin; iodonitrotetrazolium violet; and the

282 acetaldehyde dehydrogenase inhibitor disulphiram (Table 2). That the expression of a

283 kanamycin resistance gene also improves growth of ICC180 in the presence of related

284 aminoglycosides is reassuring. In contrast, the wildtype strain ICC169 was able to use the

285 nitrogen peptide Lys-Asp and grew significantly better in the presence of 8 chemicals: the metal

286 chelators, EDTA and EGTA, sodium nitrate, the antibiotics rifampicin and phenethicillin, the

287 fungicide oxycarboxin, the cyclic polypeptide colistin, the nucleoside analogue cytosine-1-b-D-

288 arabinofuranoside and (Table 2). The fact that significant differences in growth rate were

289 observed for so few conditions, provided robust and comprehensive evidence that light

290 production is near-neutral in C. rodentium ICC180.

291

292 The growth of ICC180 is not impaired in a rich laboratory medium, when compared to its

293 non-bioluminescent parent strain, but does exhibit an increased lag phase when grown

294 in a restricted medium. 
295 We grew ICC180 and ICC169 in rich (LB-Lennox) and restricted (minimal A salts with 1\% 296 glucose supplementation) laboratory media. For ICC180, we found that bioluminescence 297 strongly correlated with the bacterial counts recovered throughout the growth period in both LB298 Lennox (Spearman's $r=0.9293[95 \% \mathrm{Cl}=0.8828-0.9578], p=<0.0001$ ) and the restricted 299 medium (Spearman's $r=0.9440[95 \% \mathrm{Cl}=0.9001-0.9689], p=<0.0001$ ) (Fig. 2A \& B, 3A \& 300 B). We also found that the growth of each strain was comparable in LB-Lennox medium, with no 301 significant difference between the bacterial counts recovered over 8 hours (Fig. 2B), as 302 demonstrated by the calculated AUC values (Fig. 2C).

303

304 We also found no significant difference between the bacterial counts recovered from ICC180 305 and ICC169 growing in the restricted medium for 14 hours (mean CFU $5.67 \times 10^{8}$ [SD $2.31 \times$ $\left.30610^{8}\right]$ and $8.84 \times 10^{8}\left[S D 2.93 \times 10^{8}\right]$, respectively). However, we did find a significant difference 307 between the AUC values calculated from the bacterial counts recovered over the course of 14 308 hours ( $p=0.0078$, one-tailed Wilcoxon matched-pairs signed rank test) (Fig. 3C). We calculated the slopes of the growth curves and found that there was no difference in the rates of growth of the two strains during exponential phase. Instead, we found a significant difference between the slopes calculated during the first 4 hours of growth (1/slope values: ICC169 $=1.48 \times 10^{-7}$ [SD $\left.9.98 \times 10^{-8}\right], \operatorname{ICC} 180=2.47 \times 10^{-7}\left[\mathrm{SD} 1.10 \times 10^{-7}\right] ; \mathrm{p}=0.0041$, one-tailed Paired $t$ test), suggesting ICC180 spends longer in lag phase than ICC169 when grown in the restricted 314 medium used.

\section{ICC180 is not impaired in the Galleria mellonella infection model.}

317 We infected larvae of the Greater Wax Moth G. mellonella (waxworms) with ICC169 and 318 ICC180 in single and 1:1 mixed infections. We monitored the waxworms over a 24-48 hour 319 period for survival and disease symptoms. The Caterpillar Health Index $(\mathrm{CHI})$ is a numerical 320 scoring system which measures degree of melanisation, silk production, motility, and mortality. 
321 We found that the majority of infected waxworms succumb to C. rodentium infection (Fig. 4A),

322 which is reflected by the concurrent decrease in $\mathrm{CHI}$ score (Fig. 4B). This is in contrast to

323 waxworms injected with PBS, who all survived and consistently scored 9-10 on the CHI scale

324 throughout the experiments. We also found that the survival and symptoms of waxworms

325 infected with each strain were comparable, with no significant difference between the survival

326 curves (Fig. 4A), and calculated AUC values for the $\mathrm{CHI}$ scores (Fig. 4C). However, when we

327 directly compared ICC169 and ICC180 in mixed infections of approximately 1:1, we found a

328 significant difference in the relative abundance of the bacteria recovered from waxworms at

329 either time of death or 24 hours, whichever occurred first ( $p=0.001$, one-tailed Wilcoxon

330 matched-pairs signed rank test). Despite a slightly lower infectious dose, higher numbers of

331 ICC180 were consistently recovered from infected waxworms (Fig. 4D).

332

ICC180 is impaired in mixed but not in single infections in mice when compared to its

non-bioluminescent parent strain.

We orally gavaged groups of female $6-8$ week old C57BI/6 mice $(n=6)$ with $\sim 5 \times 10^{9} \mathrm{CFU}$ of

ICC169 and ICC180, either individually or with a 1:1 ratio of each strain. We followed the

infection dynamics by obtaining bacterial counts from stool samples (Fig. 5) and by monitoring bioluminescence from ICC180 using biophotonic imaging (Fig. 6). We found that the growth of each strain was comparable during single infections, with no significant difference between the bacterial counts recovered throughout the infection (Fig. 5A), as demonstrated by the calculated AUC values (Fig. 5B).

343 In contrast, we found a significant difference between the AUC values calculated from the

344 bacterial counts recovered from ICC180 and ICC169 during mixed infections ( $p=0.001$, one-

345 tailed Wilcoxon matched-pairs signed rank test) (Fig. 5D). Our data demonstrates that when in 346 direct competition with ICC169, ICC180 is shed at consistently lower numbers from infected 
347 animals (Fig. 5C). At the peak of infection (days 6-8), this equates to over a 10-fold difference,

348 with mice shedding a median of $1.195 \times 10^{8} \mathrm{CFU}\left(\mathrm{SD} 4.544 \times 10^{7}\right.$ ) for ICC169 compared to 9.98

$349 \times 10^{6} \mathrm{CFU}\left(\mathrm{SD} 1.544 \times 10^{7}\right)$ for ICC180. This disadvantage is reflected in the Competitive

350 Indices we calculated from bacterial counts recovered at each time point, which for ICC180

351 decreased steadily throughout the course of the infection (Fig. 5E). Despite this disadvantage,

352 ICC180 is never completely outcompeted and remains detectable in the stools of infected

353 animals until the clearance of infection (Fig. 5C), and by biophotonic imaging until day 10-13

354 post-infection (Fig. 6A).

355

356

\section{Discussion}

357 Bioluminescently-labelled bacteria have gained popularity as a powerful tool for investigating

358 microbial pathogenicity in vivo, and for preclinical drug and vaccine development ${ }^{32-35}$. Individual

359 infected and/or treated animals can be followed over time, in contrast to the large numbers of

360 animals that are euthanised at specific time points of interest for quantifying bacterial loads

361 using labour-intensive plate count methods. Most widely used is the lux operon of the terrestrial

362 bacterium $P$. luminescens, which encodes for the luciferase enzyme which catalyses the

363 bioluminescence reaction, and for a multi-enzyme complex responsible for regenerating the

364 required substrate. As $\mathrm{FMNH}_{2}$ is also required for light production, it is generally hypothesised

365 that light production is likely to impose a metabolic burden on tagged bacteria.

366

367 The impact of expression of the lux operon has been reported for a number of microbial

368 species. Sanz and colleagues created strains of Bacillus anthracis that emit light during

369 germination, by introducing plasmids with lux operon expression driven by the sspB promoter ${ }^{36}$.

370 The authors noted that the bioluminescent strains were less efficient at germinating, resulting in

371 an increase in the dose required to cause a lethal infection in mice inoculated by either the 
372 subcutaneous or intranasal route. Despite the reduced virulence, bioluminescent $B$. anthracis

373 was still capable of successfully mounting an infection, and the use of biophotonic imaging

374 revealed new infection niches which would have been difficult to accurately measure using

375 traditional plating methods. Similarly, a clinical M75 isolate of Streptococcus pyogenes with the

376 Iux operon chromosomally inserted at the spy0535 gene was found to have significantly

377 attenuated maximal growth in vitro, as well as reduced survival in an intranasal mouse model ${ }^{37}$.

378 The bioluminescent Listeria monocytogenes Xen32 strain was shown to cause reduced

379 mortality after oral inoculation of BALB/cJ mice, however subsequent investigation revealed that

380 the chromosomally-located lux operon had inserted into the flaA gene, disrupting the ability of

381 Xen32 to produce flagella. This suggests that the virulence attenuation observed is likely due to

382 the location of the lux operon rather than the metabolic cost of light production ${ }^{38}$.

383

384 In this study, we compared a bioluminescent-derivative of the mouse enteropathogen $C$.

385 rodentium, strain ICC180, with its non-bioluminescent parent strain ICC169, using the BIOLOG

Phenotypic Microarray (PM) system, which tests microbial growth under approximately 2000

387

different metabolic conditions. Rather surprisingly, our results demonstrated that the expression

388

of bioluminescence in ICC180 is near-neutral in almost every non-toxic environment tested,

389

suggesting that light production is not metabolically costly to $C$. rodentium. This supports the

"free lunch hypothesis" proposed by Falls and colleagues, namely that cells have an excess of

metabolic power available to them ${ }^{39}$. Interestingly, ICC180 grew significantly better than its non-

bioluminescent parent strain in the presence of a number of different chemicals, including

several antibiotics, supporting previous findings that bacteria have many pleiotropic ways to

resist toxins ${ }^{40}$. In the case of the artificial electron acceptor iodonitrotetrazolium violet, we dye less toxic. 
398 We also compared the ability of ICC180 and ICC169 to directly compete with one another 399 during infection of their natural host, laboratory mice, as well as larvae of the Greater Wax Moth 400 G. mellonella (waxworms). Wax worms are becoming an increasingly popular surrogate host for 401 infectious diseases studies due to legislative requirements in many countries to replace the use 402 of animals in scientific research. Wax worms have a well-developed innate immune system 403 involving a cellular immune response in the form of haemocytes, and a humoral immune 404 response in the form of antimicrobial peptides in the hemolymph ${ }^{41}$. Detection of bacterial cell 405 wall components leads to activation of the prophenoloxidase cascade, which is similar to the 406 complement system in mammals ${ }^{42}$, and subsequent endocytosis of bacteria by haemocytes. 407 The haemocytes function in a similar way to mammalian neutrophils, and kill bacteria via 408 NADPH oxidase and production of reactive oxygen species ${ }^{43}$. Again, we observed no fitness 409 costs to constitutive light production by ICC 180. Interestingly, we recovered significantly more 410 ICC180 from wax worms infected with both ICC180 and ICC169. Similar to the response to 411 iodonitrotetrazolium violet, an altered redox balance caused by light production could make 412 reactive oxygen species generated by the wax worm immune response, less toxic.

414 In contrast, our data shows that the non-bioluminescent parent strain ICC169 has a clear 415 competitive advantage over ICC180 during infection of adult C57BI/6 mice, with the 416 bioluminescent strain shed from infected animals at consistently lower numbers. Surprisingly 417 though, this competitive advantage is not sufficient for the parent strain to entirely outcompete 418 and displace its bioluminescent derivative, which remains present in the gastrointestinal tract 419 until clearance of both strains by the immune system. This suggests that there are sufficient 420 niches within the gastrointestinal tract for the two strains to coexist. 
422 It is important to note that in addition to light production, ICC180 differs from its non-

423 bioluminescent parent strain ICC169 by lacking a putative site-specific DNA recombinase,

424 disrupted by insertion of the Iux operon. C. rodentium ICC180 was constructed by random

425 transposon mutagenesis of ICC169 with a mini-Tn5 vector containing an unpromoted lux operon

426 and kanamycin-resistance gene. Previous characterisation of the site of insertion of the lux

427 operon suggested that the transposon had inserted within a homologue of the xylE gene.

428 However, whole genome sequencing has revealed that this was incorrect and the lux operon

429 has inserted at 5,212,273 bp, disrupting the coding region of the putative site-specific DNA

430 recombinase. Whole genome sequencing also revealed that ICC180 differs from ICC169 by 2

431 non-synonymous SNPs, a single base pair insertion and a $90 \mathrm{bp}$ deletion. It is unclear if these

432 changes occurred during the process of transposon mutagenesis, and are merely 'hitch-hikers',

433 or after laboratory passage. The single base pair insertion revealed by sequencing is of a $G$

434 residue at 3,326,092 bp which results in a frameshift mutation within a putative membrane

435 transporter, while the $90 \mathrm{bp}$ deletion is within the deoxyribose operon repressor gene deoR. The

436 DeoR protein represses the deoCABD operon, which is involved in the catabolism of

437 deoxyribonucleotides. One SNP is the substitution of an aspartic acid (D) for a glycine (G) at

438 residue 471 of Cts $1 \mathrm{~V}$, a Type 6 secretion system protein involved in ATP binding. The other

439 SNP is the substitution of a glutamic acid (E) for a glycine (G) at residue 89 of the formate

440 acetyletransferase 2 gene $p f I D$, which is involved in carbon utilisation under anaerobic

441 conditions. Modelling suggests that once mutated, residue 89 will be unable to make several

442 key contacts, suggesting the function of PfID will be affected. As we have not introduced these

443 genetic differences into the non-bioluminescent parent strain, we cannot be certain whether the

444 fitness costs we observed are a result of any single or combination of these differences, or

445 expression of the lux operon. In addition, at $54 \mathrm{~kb}$ the largest C. rodentium plasmid pCROD1 is

446 dramatically altered in ICC180, missing 41 out of 60 of genes. This is in contrast to previous

447 results which indicated that pCROD1 is entirely absent in ICC180 ${ }^{44}$. We do not anticipate that 
448 the loss of a large part of this plasmid will have any significant impact however, as it has been

449 shown that pCROD1 is frequently lost in C. rodentium, and that strains lacking pCROD1 do not

450 show any attenuation of virulence in a C57BL/6 mouse model ${ }^{44}$.

451

452 In conclusion, the bioluminescent $C$. rodentium strain ICC180 has a clear disadvantage when

453 directly competed with its parent stain in mice. However, the fact that it reaches similar

454 numbers, and causes similar pathology ${ }^{11,14}$, during single infections is reassuring. Our

455 phenotypic microarray data suggests that constitutive light expression is surprisingly neutral in

456 C. rodentium and supports the view that bioluminescent versions of microbes can be used as a

457 substitute for their non-bioluminescent parents, at least in theory. In reality, the actual fitness

458 costs will likely depend on the host bacterial species, whether the lux operon is located on a

459 multi-copy plasmid or integrated into the chromosome (and if chromosomal, the site of insertion

460 of the operon), and the levels of expression of the lux genes.

461

462

463

\section{References}

464 1. Vencl, F. V. Allometry and proximate mechanisms of sexual selection in photinus fireflies, 465 and some other beetles. Integr. Comp. Biol. 44, 242-9 (2004).

466 2. Meyer-Rochow, V. B. Glowworms: a review of Arachnocampa spp. and kin.

$467 \quad$ Luminescence 22, 251-65 (2007).

468 3. Jones, B. W. \& Nishiguchi, M. K. Counterillumination in the Hawaiian bobtail squid, 469 Euprymna scolopes Berry (Mollusca: Cephalopoda). Mar. Biol. 144, 1151-1155 (2004).

470 4. De Wet, J. R., Wood, K. V., Helinski, D. R. \& DeLuca, M. Cloning of firefly luciferase cDNA 471 and the expression of active luciferase in Escherichia coli. Proc. Natl. Acad. Sci. U.S.A. $472 \quad 82,7870-3(1985)$. 
473 5. Engebrecht, J., Nealson, K. \& Silverman, M. Bacterial bioluminescence: isolation and 474 genetic analysis of functions from Vibrio fischeri. Cell 32, 773-81 (1983).

475 6. Szittner, R. \& Meighen, E. Nucleotide sequence, expression, and properties of luciferase 476 coded by lux genes from a terrestrial bacterium. J. Biol. Chem. 265, 16581-7 (1990).

477 7. Andreu, N., Zelmer, A. \& Wiles, S. Noninvasive biophotonic imaging for studies of 478 infectious disease. FEMS Microbiol. Rev. 35, 360-94 (2011).

479 8. Andreu, N., Zelmer, A., Sampson, S. L., Ikeh, M., Bancroft, G. J., Schaible, U. E., Wiles, 480 S. \& Robertson B. D. Rapid in vivo assessment of drug efficacy against Mycobacterium 481 482 tuberculosis using an improved firefly luciferase. J. Antimicrob. Chemother. 68, 2118-27 (2013).

9. Andreu, N., Fletcher, T., Krishnan, N., Wiles, S. \& Robertson, B. D. Rapid measurement of antituberculosis drug activity in vitro and in macrophages using bioluminescence. J. Antimicrob. Chemother. 67, 404-14 (2012).

10. Hastings \& Presswood. Bacterial luciferase: $\mathrm{FMNH}_{2}$-aldehyde oxidase. Meth. Enzymol. 53, 558-70 (1978).

11. Wiles, S., Clare, S., Harker, J., Huett, A., Young, D., Dougan, G. \& Frankel, G. Organ specificity, colonization and clearance dynamics in vivo following oral challenges with the murine pathogen Citrobacter rodentium. Cell. Microbiol. 6, 963-72 (2004). Erratum: Cell. Microbiol. 7, 459 (2005).

12. Mundy, R., MacDonald, T. T., Dougan, G., Frankel, G. \& Wiles, S. Citrobacter rodentium of mice and man. Cell. Microbiol. 7, 1697-706 (2005).

13. Collins, J. W., Keeney, K. M., Crepin, V. F., Rathinam, V. A., Fitzgerald, K. A., Finlay, B. B. \& Frankel, G. Citrobacter rodentium: infection, inflammation and the microbiota. Nat. Rev. Microbiol. 12, 612-23 (2014). 
497

498

499

500

501

502

503

504

505

506

507

508

509

510

511

512

513

514

515

516

517

518

519

520

14. Wiles, S., Pickard, K. M., Peng, K., MacDonald, T. T. \& Frankel, G. In vivo bioluminescence imaging of the murine pathogen Citrobacter rodentium. Infect. Immun. $74,5391-6$ (2006).

15. Wiles, S., Dougan, G. \& Frankel, G. Emergence of a 'hyperinfectious' bacterial state after passage of Citrobacter rodentium through the host gastrointestinal tract. Cell. Microbiol. 7, 1163-72 (2005).

16. Winson, M. K., Swif.t S., Hill, P. J., Sims, C. M., Griesmayr, G., Bycroft, B. W., Williams, P. \& Stewart, G.S. Engineering the IuxCDABE genes from Photorhabdus luminescens to provide a bioluminescent reporter for constitutive and promoter probe plasmids and miniTn5 constructs. FEMS Microbiol. Lett. 163, 193-202 (1998).

17. Bochner, B. R., Gadzinski, P. \& Panomitros, E. Phenotype microarrays for highthroughput phenotypic testing and assay of gene function. Genome Res. 11, 1246-55 (2001).

18. Davis, B. D. The isolation of biochemically deficient mutants of bacteria by means of penicillin. Proc. Natl. Acad. Sci. U.S.A. 35, 1-10 (1949).

19. Cox, M. P., Peterson, D. A. \& Biggs, P. J. SolexaQA: At-a-glance quality assessment of Illumina second-generation sequencing data. BMC Bioinformatics 11, 485 (2010).

20. Petty, N. K., Bulgin, R., Crepin, V. F., Cerdeño-Tárraga, A. M., Schroeder, G. N., Quail, M. A., Lennard, N., Corton, C., Barron, A., Clark, L., Toribio, A. L., Parkhill, J., Dougan, G., Frankel, G. \& Thomson, N. R. The Citrobacter rodentium genome sequence reveals convergent evolution with human pathogenic Escherichia coli. J. Bacteriol. 192, 525-38 (2010).

21. Li, H. \& Durbin, R. Fast and accurate long-read alignment with Burrows-Wheeler transform. Bioinformatics 26, 589-95 (2010). 
521

522

523

524

525

526

527

528

529

530

531

532

533

534

535

536

537

538

539

540

541

542

543

544

22. Li, H., Handsaker, B., Wysoker, A., Fennell, T., Ruan, J., Homer, N., Marth, G., Abecasis, G., Durbin, R.; 1000 Genome Project Data Processing Subgroup. The Sequence Alignment/Map format and SAMtools. Bioinformatics 25, 2078-9 (2009).

23. Deatherage, D. E. \& Barrick, J. E. Identification of mutations in laboratory-evolved microbes from next-generation sequencing data using breseq. Methods Mol. Biol. 1151, 165-88 (2014).

24. Hernandez, D., François, P., Farinelli, L., Osterås, M. \& Schrenzel, J. De novo bacterial genome sequencing: millions of very short reads assembled on a desktop computer. Genome Res. 18, 802-9 (2008).

25. Kearse, M., Moir, R., Wilson, A., Stones-Havas, S., Cheung, M., Sturrock, S., Buxton, S., Cooper, A., Markowitz, S., Duran, C., Thierer, T., Ashton, B., Meintjes, P. \& Drummond, A. Geneious Basic: an integrated and extendable desktop software platform for the organization and analysis of sequence data. Bioinformatics 28, 1647-9 (2012).

26. Reuter, S., Connor, T. R., Barquist, L., Walker, D., Feltwell, T., Harris, S. R., Fookes, M., Hall, M. E., Petty, N. K., Fuchs, T. M., Corander, J., Dufour, M., Ringwood, T., Savin, C., Bouchier, C., Martin, L., Miettinen, M., Shubin, M., Riehm, J. M., Laukkanen-Ninios, R., Sihvonen, L. M., Siitonen, A., Skurnik, M., Falcão, J. P., Fukushima, H., Scholz, H. C., Prentice, M. B., Wren, B. W., Parkhill, J., Carniel, E., Achtman, M., McNally, A. \& Thomson, N.R. Parallel independent evolution of pathogenicity within the genus Yersinia. Proc. Natl. Acad. Sci. U.S.A. 111, 6768-73 (2014).

27. Homann, O. R., Cai, H., Becker, J. M. \& Lindquist, S. L. Harnessing natural diversity to probe metabolic pathways. PLOS Genet. 1, e80 (2005).

28. Smyth, G. K. Linear models and empirical bayes methods for assessing differential expression in microarray experiments. Stat. Appl. Genet. Mol. Biol. 3, Article3 (2004). 
545

546

547

548

549

550

551

552

553

554

555

556

557

558

559

560

561

562

563

564

565

566

567

568

569

570

29. Galardini, M., Mengoni, A., Biondi, E. G., Semeraro, R., Florio, A., Bazzicalupo, M., Benedetti, A. \& Mocali, S. DuctApe: A suite for the analysis and correlation of genomic and OmniLogTM Phenotype Microarray data. Genomics 103, 1-10 (2014).

30. Freter, R., O'Brien, P. C. \& Macsai, M. S. Role of chemotaxis in the association of motile bacteria with intestinal mucosa: in vivo studies. Infect. Immun. 34, 234-40 (1981).

31. Taylor, R. K., Miller, V. L., Furlong, D. B. \& Mekalanos, J. J. Use of phoA gene fusions to identify a pilus colonization factor coordinately regulated with cholera toxin. Proc. Natl. Acad. Sci. U.S.A. 84, 2833-7 (1987).

32. Sun, Y., Connor, M. G., Pennington, J. M. \& Lawrenz, M. B. Development of bioluminescent bioreporters for in vitro and in vivo tracking of Yersinia pestis. PLOS One 7, e47123 (2012)

33. Massey, S., Johnston, K., Mott, T. M., Judy, B. M., Kvitko, B. H., Schweizer, H. P., Estes, D. M. \& Torres, A. G. In vivo bioluminescence imaging of Burkholderia mallei respiratory infection and treatment in the mouse model. Front. Microbiol 2, 174 (2011).

34. Steinhuber, A., Landmann, R., Goerke, C., Wolz, C. \& Flückiger, U. Bioluminescence imaging to study the promoter activity of hla of Staphylococcus aureus in vitro and in vivo. Int. J. Med. Microbiol. 298, 599-605 (2008).

35. Kassem, I. I., Splitter, G. A., Miller, S. \& Rajashekara, G. Let there be light! Bioluminescent imaging to study bacterial pathogenesis in live animals and plants. Adv. Biochem. Eng. Biotechnol. 154, 119-45 (2016).

36. Sanz, P., Teel, L. D., Alem, F., Carvalho, H. M., Darnell, S. C. \& O'Brien, A. D. Detection of Bacillus anthracis spore germination in vivo by bioluminescence imaging. Infect. Immun. 76, 1036-47 (2008).

37. Alam, F. M., Bateman, C., Turner, C. E., Wiles, S. \& Sriskandan, S. Non-invasive monitoring of Streptococcus pyogenes vaccine efficacy using biophotonic imaging. PLOS One 8, e82123 (2013). 
571

572

573

574

575

576

577

578

579

580

581

582

583

584

585

586

587

588

589

590

591

592

593

594

595

596

38. Bergmann, S., Rohde, M., Schughart, K. \& Lengeling, A. The bioluminescent Listeria monocytogenes strain Xen32 is defective in flagella expression and highly attenuated in orally infected BALB/cJ mice. Gut. Pathog. 5, 19 (2013).

39. Falls, K., Williams, A., Bryksin, A. \& Matsumura, I. Escherichia coli deletion mutants illuminate trade-offs between growth rate and flux through a foreign anabolic pathway. PLOS One 9, e88159 (2014).

40. Soo, V. W., Hanson-Manful, P. \& Patrick, W. M. Artificial gene amplification reveals an abundance of promiscuous resistance determinants in Escherichia coli. Proc. Natl. Acad. Sci. U.S.A. 108, 1484-9 (2011).

41. Vogel, H., Altincicek, B., Glöckner, G. \& Vilcinskas, A. A comprehensive transcriptome and immune-gene repertoire of the lepidopteran model host Galleria mellonella. BMC Genomics 12, 308 (2011).

42. Park, S., Kim, C. H., Jeong, W. H., Lee, J. H., Seo, S. J., Han, Y. S. \& Lee, I. H. Effects of two hemolymph proteins on humoral defense reactions in the wax moth, Galleria mellonella. Dev. Comp. Immunol. 29, 43-51 (2005).

43. Bergin, D., Reeves, E., Renwick, J., Wientjes, F. \& Kavanagh, K. Superoxide production in Galleria mellonella hemocytes: identification of proteins homologous to the NADPH oxidase complex of human neutrophils. Infect. Immun. 73, 4161-4170 (2005).

44. Petty, N. K., Feltwell, T., Pickard, D., Clare, S., Toribio, A. L., Fookes, M., Roberts, K., Monson, R., Nair, S., Kingsley, R. A., Bulgin, R., Wiles, S., Goulding, D., Keane, T., Corton, C., Lennard, N., Harris, D., Willey, D., Rance, R., Yu, L., Choudhary, J. S., Churcher, C., Quail, M. A., Parkhill, J., Frankel, G., Dougan, G., Salmond, G. P. \& Thomson, N. R. Citrobacter rodentium is an unstable pathogen showing evidence of significant genomic flux. PLOS Path. 7, e1002018 (2011). 


\section{Acknowledgements}

598 This work was supported by seed funding from the Maurice Wilkins Centre for Molecular

599 Biodiscovery, and by a Sir Charles Hercus Fellowship to SW (09/099) from the Health Research

600 Council of New Zealand. LB is supported by a Research Fellowship from the Alexander von

601 Humboldt Stiftung/Foundation.

602

603

604 
605

606 Tables

607

\begin{tabular}{|l|l|l|l|l|}
\hline Position & Base & Amino acid change & Gene & Function \\
\hline $2,936,285$ & $\mathrm{~T} \rightarrow \mathrm{C}$ & D471G $(\mathrm{GAC} \rightarrow \mathrm{GGC})$ & cts1V & T6SS protein Cts1V \\
\hline $3,999,002$ & $\mathrm{~T} \rightarrow \mathrm{C}$ & E89G (GAG $\rightarrow \mathrm{GGG})$ & $p f I D$ & Formate acetyltransferase 2 \\
\hline $3,326,092$ & CAG $\rightarrow$ & Frameshift & ROD_ & Major Facilitator Superfamily \\
& CAGG & & 31611 & transporter \\
\hline
\end{tabular}

608

609 Table 1. SNPs and indels that differ between the bioluminescent $C$. rodentium derivative

610 ICC180 and its parent strain ICC169. Sequencing revealed three points of difference between

611 ICC180 and ICC169. Two SNPs are present, each cytosine substitutions, and one guanine

612 insertion inducing a frameshift mutation. Sequencing data was analysed using BreSeq ${ }^{23}$.

613

614

615 
616

617

\begin{tabular}{|c|c|c|c|c|c|}
\hline PM Class & Substrate & $\begin{array}{l}\text { Adjusted } \\
\mathrm{p} \text { value }\end{array}$ & $\begin{array}{l}\text { Improved } \\
\text { growth by } \\
\text { ICC169 }\end{array}$ & $\begin{array}{l}\text { Improved } \\
\text { growth by } \\
\text { ICC180 }\end{array}$ & Comment \\
\hline \multirow[t]{3}{*}{ Nitrogen } & D-glucosamine & 0.0159 & & $\boldsymbol{\nu}$ & \\
\hline & Cytidine & 0.0280 & & $\checkmark$ & \\
\hline & Ala-His & 0.0316 & & $\checkmark$ & \\
\hline Phosphate & $\begin{array}{l}\text { Inositol } \\
\text { hexaphosphate }\end{array}$ & 0.0280 & & $\checkmark$ & \\
\hline $\begin{array}{l}\text { Nitrogen } \\
\text { peptides }\end{array}$ & Lys-Asp & 0.0306 & $\checkmark$ & & \\
\hline \multirow[t]{10}{*}{ Chemicals } & Kanamycin & 0.0076 & & $\boldsymbol{\nu}$ & Conferred by KanR gene \\
\hline & Paromomycin & 0.0048 & & $\checkmark$ & $\begin{array}{l}\text { Aminoglycoside -- the kanamycin } \\
\text { cassette will be mediating } \\
\text { resistance }\end{array}$ \\
\hline & Geneticin & 0.0048 & & $\checkmark$ & $\begin{array}{l}\text { Aminoglycoside -- the kanamycin } \\
\text { cassette will be mediating } \\
\text { resistance }\end{array}$ \\
\hline & $\begin{array}{l}\text { Dequalinium } \\
\text { chloride }\end{array}$ & 0.0116 & & $\checkmark$ & Quaternary ammonium salt \\
\hline & Spiramycin & 0.0088 & & $\checkmark$ & $\begin{array}{l}\text { Macrolide -- acts at ribosomal 50S, } \\
\text { c.f. aminoglycosides at } 30 \mathrm{~S}\end{array}$ \\
\hline & Rolitetracycline & 0.0316 & & $\checkmark$ & $\begin{array}{l}\text { Tetracycline; prevents tRNA } \\
\text { binding at } 30 \mathrm{~S} \text { A-site }\end{array}$ \\
\hline & Doxycycline & 0.0210 & & $\checkmark$ & $\begin{array}{l}\text { Tetracycline; prevents tRNA } \\
\text { binding at } 30 \mathrm{~S} \text { A-site }\end{array}$ \\
\hline & Coumarin & 0.0333 & & $\checkmark$ & $\begin{array}{l}\text { Fragrant organic compound found } \\
\text { in many plants }\end{array}$ \\
\hline & $\begin{array}{l}\text { lodonitro } \\
\text { tetrazolium violet } \\
\text { (INT) }\end{array}$ & 0.0087 & & $\checkmark$ & $\begin{array}{l}\text { Electron acceptor, reduced by } \\
\text { succinate dehydrogenase (and by } \\
\text { superoxide radicals) }\end{array}$ \\
\hline & EDTA & 0.0048 & $\checkmark$ & & Metal chelator \\
\hline
\end{tabular}




\begin{tabular}{|c|c|c|c|c|}
\hline EGTA & 0.0210 & $\boldsymbol{\sim}$ & & Metal chelator \\
\hline Rifampicin & 0.0048 & $\checkmark$ & & RNA polymerase inhibitor \\
\hline Colistin & 0.0048 & $\checkmark$ & & $\begin{array}{l}\text { Cyclic polypeptide; disrupts outer } \\
\text { membrane }\end{array}$ \\
\hline Oxycarboxin & 0.0121 & $\checkmark$ & & Fungicide \\
\hline Phenethicillin & 0.0048 & $\checkmark$ & & Beta-lactam \\
\hline $\begin{array}{l}\text { Cytosine-1-b-D- } \\
\text { arabinofuranosid } \\
\text { e }\end{array}$ & 0.0123 & $\nu$ & & $\begin{array}{l}\text { Nucleoside analogue (anti-cancer/- } \\
\text { viral) }\end{array}$ \\
\hline Sodium Nitrate & 0.0306 & $\nu$ & & \\
\hline Cefoxitin & 0.0316 & & $\checkmark$ & Beta-lactam \\
\hline Disulphiram & 0.0349 & & $\boldsymbol{v}$ & $\begin{array}{l}\text { Inhibits acetaldehyde } \\
\text { dehydrogenase }\end{array}$ \\
\hline
\end{tabular}

\section{8}

619 Table 2. Phenotypic microarray (PM) wells in which the growth of bioluminescent $\boldsymbol{C}$. 620 rodentium derivative ICC180 significantly differs from its non-bioluminescent parent 621 strain ICC169. 
622

623 Figure legends

624

625

Figure 1. Whole genome sequencing shows that the lux operon and kanamcyin

626

resistance gene have inserted at position $5,212,273$ in the chromosome of $C$. rodentium

627

ICC180, disrupting a putative site-specific DNA recombinase.

628

629

630

Figure 2. C. rodentium ICC180 is not impaired during growth in a rich laboratory medium

631 when compared to its non-bioluminescent parent strain ICC169. Wildtype $C$. rodentium

632

ICC169 (shown as purple circles) and its bioluminescent derivative ICC180 (shown as blue

633 triangles) were grown in LB-Lennox broth and monitored for changes in bioluminescence (given as relative light units [RLU] ml-1) (A) and bacterial counts (given as colony forming units [CFU] $\mathrm{ml}^{-1}$ ) (B). Bacterial count data was used to calculate area under curve (AUC) values for each strain (C). Data (medians with ranges where appropriate) is presented from experiments performed on eight separate occasions.

638

Figure 3. C. rodentium ICC180 is mildly impaired during growth in a defined minimal laboratory medium when compared to its non-bioluminescent parent strain ICC169. Wildtype C. rodentium ICC169 (shown as purple circles) and its bioluminescent derivative

642 ICC180 (shown as blue triangles) were grown in minimal A salts supplemented with $1 \%$ glucose 643 and monitored for changes in bioluminescence (given as relative light units [RLU] ml-1) $(A)$ and 644 bacterial counts (given as colony forming units [CFU] ml-1) (B). Bacterial count data was used to 645 calculate area under curve (AUC) values for each strain, which were found to be significantly 646 different ( $p=0.0078$; Wilcoxon Matched pairs-signed rank test) $(C)$. Data (medians with ranges 647 where appropriate) is presented from experiments performed on eight separate occasions. 
648

649 Figure 4. Bioluminescent C. rodentium ICC180 is not impaired in the Galleria mellonella 650 infection model. Groups of larvae $(n=10)$ of the Greater Wax Moth Galleria mellonella were 651 infected with ICC169 and ICC180 in single and 1:1 mixed infections and monitored for survival $652(\%)(\mathrm{A})$ and for disease symptoms using the Caterpillar Health Index ( $\mathrm{CHI})$, a numerical scoring 653 system which measures degree of melanisation, silk production, motility, and mortality (given as 654 median $\mathrm{CHI}$ values) (B). Survival curves (A) and calculated area under curve (AUC) data of $\mathrm{CHI}$ 655 scores reveals no difference between waxworm response to infection from either strain (C).

656 Waxworms infected with a 1:1 mix of ICC169 and ICC180 were homogenised at 24-hours, or at 657 time of death if earlier. Actual infecting doses for each strain were determined by retrospective 658 plating, and are indicated by *.The bacterial burden of ICC180 and ICC169 in individual

659 caterpillars (indicated by the dotted line), was calculated after plating onto differential media and 660 found to be significantly different ( $p=0.001$; one-tailed Wilcoxon matched pairs-signed rank test) 661 (D). Data (medians with ranges where appropriate) is presented from experiments performed on 6623 separate occasions, except (A) and (D), where the results of a representative experiment are 663 shown.

664

665

Figure 5. C. rodentium ICC180 is impaired during mixed, but not in single, infections in 666 mice when compared to its non-bioluminescent parent strain ICC169. Groups of female 68 week old C57BI/6 mice $(n=6)$ were orally-gavaged with $\sim 5 \times 10^{9} \mathrm{CFU}$ of wildtype C. rodentium ICC169 (shown as purple circles) and its bioluminescent derivative ICC180 (shown as blue triangles) in single infections $(A, B)$ or 1:1 mixed infections $(C, D)$ and monitored for changes in

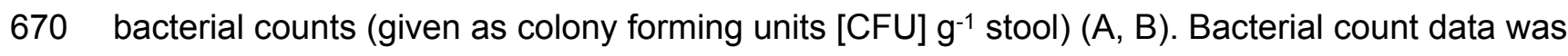
671 used to calculate area under curve (AUC) values for each strain in single (B) and mixed (D) 672 infections, and were found to be significantly different only for the mixed infections $(p=0.001$;

673 one-tailed Wilcoxon Matched pairs-signed rank test). This is reflected in the competitive indices 
$674(\mathrm{Cl})$ calculated from the bacterial counts recovered during mixed infections, with ICC180

675 showing a growing competitive disadvantage from day 2 post-infection (E). Data (medians with

676 ranges where appropriate) is presented from experiments performed on two separate

677 occasions.

678

679 Figure 6. Despite having a fitness disadvantage in mixed infections of mice, ICC180 is 680 still visible by biophotonic imaging. Groups of female $6-8$ week old C57BI/6 mice $(n=6)$ were 681 orally-gavaged with $\sim 5 \times 10^{9} \mathrm{CFU}$ of wildtype C. rodentium ICC169 and its bioluminescent 682 derivative ICC180 in single infections or 1:1 mixed infections. Mice were anaesthetised with 683 gaseous isoflurane and bioluminescence (given as photons second ${ }^{-1} \mathrm{~cm}^{-2} \mathrm{sr}^{-1}$ ) from ICC180 684 measured using the IVIS ${ }^{\circledR}$ Kinetic camera system (Perkin Elmer). The images show changes in 685 peak bioluminescence over time with variations in colour representing light intensity at a given location and superimposed over a grey-scale reference image $(A)$. Red represents the most intense light emission, whereas blue corresponds to the weakest signal. Bioluminescence from interest tool in the Living Image software program and used to calculate area under curve (AUC) values for each individual animal over the course of the infection (B). Dotted line represents background. Experiments were performed on two separate occasions. Three representative animals are shown; no light was detected from animals infected with ICC169 alone, while lower levels of light were detected from animals infected with a mix of ICC169 and ICC180. number of clusters appropriate for k-means clustering. Data was analysed using the DuctApe software suite. 
700 Supplementary Fig. 2. The growth of C. rodentium ICC180 compared to its non-

701 bioluminescent parent strain ICC169 as assessed by phenotypic microarray (PM).

702 Wildtype C. rodentium ICC169 and its bioluminescent derivative ICC180 were grown on two 703 separate occasions using PM plates 1-20. Activity rings from the PM data are shown where the 704 grey inner circles indicate the strains' order and the external circle indicates the PM categories 705 (see Key). The activity index (AV) was calculated for each strain in response to each well and 706 the values for ICC169 are shown as colour stripes going from red (AV = 0 [not active]) to green 707 (AV = 6 [active]; 7 total $k$-means clusters.

708

709

Supplementary Fig. 3. Phenotypic microarray (PM) growth curves of C. rodentium ICC180 and its non-bioluminescent parent strain ICC169 which are significantly different.

711 Wildtype C. rodentium ICC169 (shown as purple lines) and its bioluminescent derivative ICC180

712 (shown as blue lines) were grown on two separate occasions using PM plates 1-20 (categorised 713 by colour [see Key]). Differences between the growth of ICC169 and ICC180 in each individual well were analysed using the moderated t-test provided by limma ${ }^{28}$. Wells in which the differences had an adjusted p-value of less than 0.5 (stringent cut-off) are shown.

716

717 Supplementary Fig. 4. Infection of larvae of the Greater Wax Moth Galleria mellonella with

718 bioluminescent $C$. rodentium ICC180 can be visualised by luminometry. Groups of larvae

$719(n=10)$ of the Greater Wax Moth Galleria mellonella were infected with $\sim 10^{8}$ CFU of $C$.

720 rodentium ICC169 or ICC180 and monitored for bioluminescence using a plate luminometer.

721 Data (medians with ranges) is presented from experiments performed on 3 separate occasions 722 and is given as relative light units [RLU] waxworm ${ }^{-1}$.

723

724 


\section{Supplementary Table 1. BIOLOG Phenotypic Microarray assays.}

PM1 - Carbon

Sources

PM2 - Carbon

Sources

PM3 - Nitrogen

Sources
A1, Negative Control; A2, L-Arabinose; A3, N-Acetyl-D Glucosamine; A4, D-Saccharic Acid; A5, Succinic Acid; A6, D-Galactose; A7, L-Aspartic Acid; A8, L-Proline; A9, DAlanine; A10, D-Trehalose; A11, D-Mannose; A12, Dulcitol; B1, D-Serine; B2, D-Sorbitol; B3, Glycerol; B4, L-Fucose; B5, D-Glucuronic Acid; B6, D-Gluconic Acid; B7, D,L-aGlycerol Phosphate; B8, D-Xylose; B9, L-Lactic Acid; B10, Formic Acid; B11, D-Mannitol; B12, L-Glutamic Acid; C1, D-Glucose-6-Phosphate; C2, D-Galactonic Acid-y-Lactone; C3, D,L-Malic Acid; C4, D-Ribose; C5, Tween 20; C6, L-Rhamnose; C7, D-Fructose; C8, Acetic Acid; C9, a-D-Glucose; C10, Maltose; C11, D-Melibiose; C12, Thymidine; D1, LAsparagine; D2, D-Aspartic Acid; D3, D-Glucosaminic Acid; D4, 1,2- Propanediol; D5, Tween 40; D6, a -Keto-Glutaric Acid; D7, a -Keto-Butyric Acid; D8, a -Methyl-D Galactoside; D9, a -D-Lactose; D10, Lactulose; D11, Sucrose; D12, Uridine; E1, LGlutamine; E2, m-Tartaric Acid; E3, D-Glucose-1-Phosphate; E4, D-Fructose-6Phosphate; E5, Tween 80; E6, a-Hydroxy Glutaric Acid-a-Lactone; E7, a-Hydroxy Butyric Acid; E8, a-Methyl-DGlucoside; E9, Adonitol; E10, Maltotriose; E11, 2-Deoxy Adenosine; E12, Adenosine; F1, Glycyl-L-Aspartic Acid; F2, Citric Acid; F3, m-Inositol; F4, DThreonine; F5, Fumaric Acid; F6, Bromo Succinic Acid; F7, Propionic Acid; F8, Mucic Acid; F9, Glycolic Acid; F10, Glyoxylic Acid; F11, D-Cellobiose; F12, Inosine; G1, GlycylL-Glutamic Acid; G2, Tricarballylic Acid; G3, L-Serine; G4, L-Threonine; G5,L-Alanine; G6, L-Alanyl-Glycine; G7, Acetoacetic Acid; G8, N-Acetyl- $\beta$-D-Mannosamine; G9, Mono Methyl Succinate; G10, Methyl Pyruvate; G11, D-Malic Acid; G12, L-Malic Acid; H1, Glycyl-L-Proline; H2, p-Hydroxy Phenyl Acetic Acid; H3, m-Hydroxy Phenyl Acetic Acid; H4, Tyramine; H5, D-Psicose; H6, L-Lyxose; H7, Glucuronamide; H8, Pyruvic Acid; H9, L-Galactonic Acid-y-Lactone; H10, D-Galacturonic Acid; H11, Phenylethylamine; H12, 2Amino Ethanol.

A1, Negative Control; A2, Chondroitin Sulfate C; A3, $\alpha$-Cyclodextrin; A4, $\beta$-Cyclodextrin; A5, y-Cyclodextrin; A6, Dextrin; A7, Gelatin; A8, Glycogen; A9, Inulin; A10, Laminarin; A11, Mannan; A12, Pectin; B1, N-Acetyl-D Galactosamine; B2, N-Acetyl Neuraminic Acid; B3, $\beta$-D-Allose; B4, Amygdalin; B5, D-Arabinose; B6, D-Arabitol; B7, L-Arabitol; B8, Arbutin; B9, 2-Deoxy-D Ribose; B10, i-Erythritol; B11, D-Fucose; B12,3-0- $\beta-D-$ Galactopyranosyl-D Arabinose; C1, Gentiobiose; C2, L-Glucose; C3, Lactitol; C4, DMelezitose; C5, Maltitol; C6, a-Methyl-D Glucoside; C7, $\beta$-Methyl-D Galactoside; C8, 3Methyl Glucose; C9, $\beta$-Methyl-D Glucuronic Acid; C10, $\alpha$-Methyl-D Mannoside; C11, $\beta$ Methyl-D Xyloside; C12, Palatinose; D1, D-Raffinose; D2, Salicin; D3, Sedoheptulosan; D4, L-Sorbose; D5, Stachyose; D6, D-Tagatose; D7, Turanose; D8, Xylitol; D9, N-AcetylD Glucosaminitol; D10, y-Amino Butyric Acid; D11, ठ-Amino Valeric Acid; D12, Butyric Acid; E1, Capric Acid; E2, Caproic Acid; E3, Citraconic Acid; E4, Citramalic Acid; E5, DGlucosamine; E6, 2-Hydroxy Benzoic Acid; E7, 4-Hydroxy Benzoic Acid; E8, $\beta$-Hydroxy Butyric Acid; E9, ס-Hydroxy Butyric Acid; E10, a-Keto-Valeric Acid; E11, Itaconic Acid; E12, 5-Keto-D Gluconic Acid; F1, D-Lactic Acid Methyl Ester; F2, Malonic Acid; F3, Melibionic Acid; F4, Oxalic Acid; F5, Oxalomalic Acid; F6, Quinic Acid; F7, D-Ribono-1,4Lactone; F8, Sebacic Acid; F9, Sorbic Acid; F10, Succinamic Acid; F11, D-Tartaric Acid; F12, L-Tartaric Acid; G1, Acetamide; G2, L-Alaninamide; G3, N-Acetyl-L Glutamic Acid; G4, L-Arginine; G5, Glycine; G6, L-Histidine; G7, L-Homoserine; G8, Hydroxy-L Proline; G9, L-Isoleucine; G10, L-Leucine; G11, L-Lysine; G12, L-Methionine; H1, L-Ornithine; $\mathrm{H}$ 2, L-Phenylalanine; H3, L-Pyroglutamic Acid; H4, L-Valine; H5, D, L-Carnitine; H6, SecButylamine; H7, D.L-Octopamine; H8, Putrescine; H9, Dihydroxy Acetone; H10, 2,3Butanediol; H11, 2,3-Butanone; H12, 3-Hydroxy 2-Butanone.

A1, Negative Control; A2, Ammonia; A3, Nitrite; A4, Nitrate; A5, Urea; A6, Biuret; A7, LAlanine; A8, L-Arginine; A9, L-Asparagine; A10, L-Aspartic Acid; A11, L-Cysteine; A12, L- 


\begin{tabular}{|c|c|}
\hline & $\begin{array}{l}\text { Glutamic Acid; B1, L-Glutamine; B2, Glycine; B3, L-Histidine; B4, L-Isoleucine; B5, L- } \\
\text { Leucine; B6, L-Lysine; B7, L-Methionine; B8, L-Phenylalanine; B9, L-Proline; B10, L- } \\
\text { Serine; B11, L-Threonine; B12, L-Tryptophan; C1, L-Tyrosine; C2, L-Valine; C3, D- } \\
\text { Alanine; C4, D-Asparagine; C5, D-Aspartic Acid; C6, D-Glutamic Acid; C7, D-Lysine; C8, } \\
\text { D-Serine; C9, D-Valine; C10, L-Citrulline; C11, L-Homoserine; C12, L-Ornithine; D1, N- } \\
\text { Acetyl-L Glutamic Acid; D2, N-Phthaloyl-L Glutamic Acid; D3, L-Pyroglutamic Acid; D4, } \\
\text { Hydroxylamine; D5, Methylamine; D6, N-Amylamine; D7, N-Butylamine; D8, Ethylamine; } \\
\text { D9, Ethanolamine; D10, Ethylenediamine; D11, Putrescine; D12, Agmatine; E1, } \\
\text { Histamine; E2, ß-Phenylethylamine; E3, Tyramine; E4, Acetamide; E5, Formamide; E6, } \\
\text { Glucuronamide; E7, D,L-Lactamide; E8, D-Glucosamine; E9, D-Galactosamine; E10, D- } \\
\text { Mannosamine; E11, N-Acetyl-D Glucosamine; E12, N-Acetyl-D Galactosamine; F1, N- } \\
\text { Acetyl-D Mannosamine; F2, Adenine; F3, Adenosine; F4, Cytidine; F5, Cytosine; F6, } \\
\text { Guanine; F7, Guanosine; F8, Thymine; F9, Thymidine; F10, Uracil; F11, Uridine; F12, } \\
\text { Inosine; G1, Xanthine; G2, Xanthosine; G3, Uric Acid; G4, Alloxan; G5, Allantoin; G6, } \\
\text { Parabanic Acid; G7, D,L-a-Amino-N Butyric Acid; G8, B-Amino-N Butyric Acid; G9, ع- } \\
\text { Amino-N Caproic Acid; G10, D,L-a-Amino Caprylic Acid; G11, D-Amino-N Valeric Acid; } \\
\text { G12, a-Amino-N Valeric Acid; H1, Ala-Asp; H2, Ala-Gln; H3, Ala-Glu; H4, Ala-Gly; H5, } \\
\text { Ala-His; H6, Ala-Leu; H7, Ala-Thr; H8, Gly-Asn; H9, Gly-Gln; H10, Gly-Glu; H11, Gly-Met; } \\
\text { H12, Met-Ala. }\end{array}$ \\
\hline $\begin{array}{l}\text { PM4 - Phosphorus } \\
\text { and Sulfur Sources }\end{array}$ & 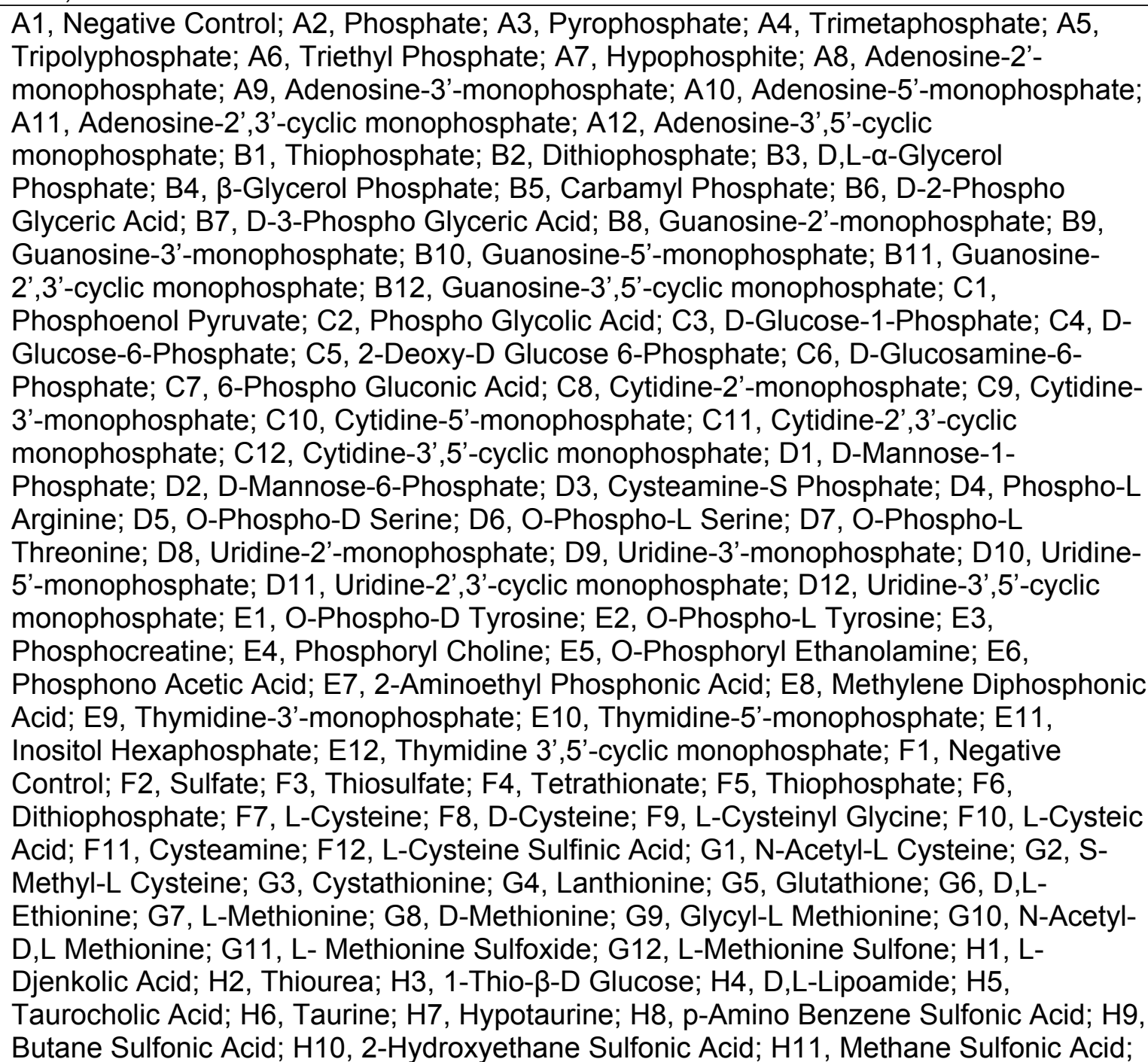 \\
\hline
\end{tabular}




\begin{tabular}{|c|c|}
\hline & H12, Tetramethylene Sulfone. \\
\hline $\begin{array}{l}\text { PM5 - Nutrient } \\
\text { Supplements }\end{array}$ & 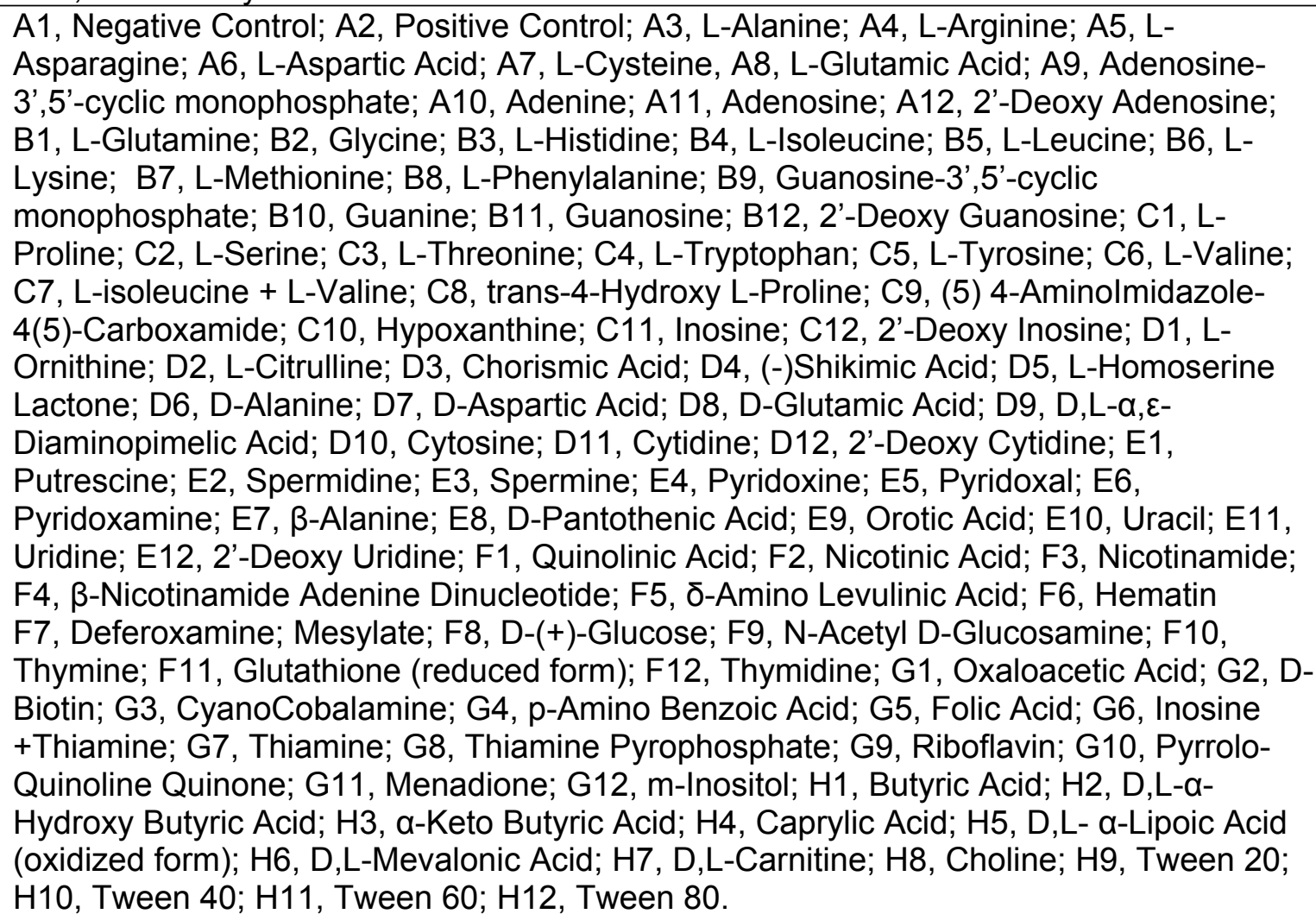 \\
\hline $\begin{array}{l}\text { PM6 - Peptide } \\
\text { Nitrogen sources }\end{array}$ & $\begin{array}{l}\text { A1, Negative Control; A2, Positive Control: L-Glutamine; A3, Ala-Ala; A4, Ala-Arg; A5, } \\
\text { Ala-Asn; A6, Ala-Glu; A7, Ala-Gly; A8, Ala-His; A9, Ala-Leu; A10, Ala-Lys; A11, Ala-Phe; } \\
\text { A12, Ala-Pro; B1, Ala-Ser; B2, Ala-Thr; B3, Ala-Trp; B4, Ala-Tyr; B5, Arg-Ala; B6, Arg- } \\
\text { Arg; B7, Arg-Asp; B8, Arg-Gln; B9, ; rg-Glu; B10, Arg-Ile; B11, Arg-Leu; B12, Arg-Lys; } \\
\text { C1, Arg-Met; C2, Arg-Phe; C3, Arg-Ser; C4, Arg-; rp; C5, Arg-Tyr; C6, Arg-Val; C7, Asn- } \\
\text { Glu; C8, Asn-Val; C9, Asp-Asp; C10, Asp-Glu; C11, Asp-Leu; C12, Asp-Lys; D1, Asp- } \\
\text { Phe; D2, Asp-Trp; D3, Asp-Val; D4, Cys-Gly; D5, Gln-Gln ;D6, Gln-Gly; D7, Glu-Asp; D8, } \\
\text { Glu-Glu; D9, Glu-Gly; D10, Glu-Ser; D11, Glu-Trp; D12, Glu-Tyr; E1, Glu-Val; E2, Gly- } \\
\text { Ala; E3, Gly-Arg; E4, Gly-Cys; E5, Gly-Gly; E6, Gly-His; E7, Gly-Leu; E8, Gly-Lys; E9, } \\
\text { Gly-Met; E10, Gly-Phe; E11, Gly-Pro; E12, Gly-Ser; F1, Gly-Thr; F2, Gly-Trp; F3, Gly- } \\
\text { Tyr; F4, Gly-Val; F5, His-Asp; F6, His-Gly; F7, His-Leu; F8, His-Lys; F9, His-Met; F10, } \\
\text { His-Pro; F11 ,His-Ser; F12, His-Trp; G1, His-Tyr; G2, His-Val; G3, Ile-Ala; G4, Ile-Arg; } \\
\text { G5, Ile-Gln; G6, Ile-Gly; G7, Ile-His; G8, Ile-Ile; G9, Ile-Met; G10, Ile-Phe; G11, Ile-Pro; } \\
\text { G12, Ile-Ser; H1, Ile-Trp; H2, Ile-Tyr; H3, Ile-Val; H4, Leu-Ala; H5, Leu-Arg; H6, Leu-Asp; } \\
\text { H7, Leu-Glu; H8, Leu-Gly; H9, Leu-Ile; H10, Leu-Leu; H11, Leu-Met; H12, Leu-Phe. }\end{array}$ \\
\hline $\begin{array}{l}\text { PM7 - Peptide } \\
\text { Nitrogen sources }\end{array}$ & $\begin{array}{l}\text { A1, Negative Control; A2, Positive Control: L-Glutamine; A3, Leu-Ser; A4, Leu-Trp; A5, } \\
\text { Leu-Val; A6, Lys-Ala; A7, Lys-Arg; A8, Lys-Glu; A9, Lys-lle; A10, Lys-Leu; A11, Lys-Lys; } \\
\text { A12, Lys-Phe; B1, Lys-Pro; B2, Lys-Ser; B3, Lys-Thr; B4, Lys-Trp; B5 ,Lys-Tyr; B6, Lys- } \\
\text { Val; B7, Met-Arg; B8, Met-Asp; B9, Met-GIn; B10, Met-Glu; B11, Met-Gly; B12, Met-His; } \\
\text { C1, Met-Ile; C2, Met-Leu; C3, Met-Lys; C4, Met-Met; C5, Met-Phe; C6, Met-Pro; C7, Met- } \\
\text { Trp; C8, Met-Val; C9, Phe-Ala; C10, Phe-Gly; C11, Phe-lle; C12, Phe-Phe; D1, Phe-Pro; } \\
\text { D2, Phe-Ser; D3, Phe-Trp; D4, Pro-Ala; D5, Pro-Asp; D6, Pro-GIn; D7, Pro-Gly; D8, Pro- } \\
\text { Hyp; D9, Pro-Leu; D10, Pro-Phe; D11, Pro-Pro; D12, Pro-Tyr; E1, Ser-Ala; E2, Ser-Gly; } \\
\text { E3, Ser-His; E4, Ser-Leu; E5, Ser-Met; E6, Ser-Phe; E7, Ser-Pro; E8, Ser-Ser; E9, Ser- } \\
\text { Tyr; E10, Ser-Val; E11, Thr-Ala; E12, Thr-Arg; F1, Thr-Glu; F2, Thr-Gly; F3, Thr-Leu; F4, } \\
\text { Thr-Met; F5, Thr-Pro; F6, Trp-Ala; F7, Trp-Arg; F8, Trp-Asp; F9, Trp-Glu; F10, Trp-Gly; }\end{array}$ \\
\hline
\end{tabular}




\begin{tabular}{|c|c|}
\hline & $\begin{array}{l}\text { F11, Trp-Leu; F12, Trp-Lys; G1, Trp-Phe; G2, Trp-Ser; G3, Trp-Trp; G4, Trp-Tyr; G5, } \\
\text { Tyr-Ala; G6, Tyr-GIn; G7, Tyr-Glu; G8, Tyr-Gly G9, Tyr-His; G10, Tyr-Leu; G11, Tyr-Lys; } \\
\text { G12, Tyr-Phe; H1, Tyr-Trp; H2, Tyr-Tyr; H3, Val-Arg; H4, Val-Asn; H5, Val-Asp; H6, Val- } \\
\text { Gly; H7, Val-His; H8, Val-Ile; H9, Val-Leu; H10, Val-Tyr; H11, Val-Val; H12, Y-Glu-Gly. }\end{array}$ \\
\hline $\begin{array}{l}\text { PM8 - Peptide } \\
\text { Nitrogen sources }\end{array}$ & $\begin{array}{l}\text { A1, Negative Control; A2, Positive Control: L-Glutamine; A3, Ala-Asp; A4, Ala-Gln; A5, } \\
\text { Ala-Ile; A6, Ala-Met; A7, Ala-Val; A8, Asp-Ala; A9, Asp-Gln; A10, Asp-Gly; A11, Glu-Ala; } \\
\text { A12, Gly-Asn; B1, Gly-Asp; B2, Gly-lle; B3, His-Ala; B4, His-Glu; B5, His-His; B6, Ile-Asn; } \\
\text { B7, Ile-Leu; B8, Leu-Asn; B9, Leu-His; B10, Leu-Pro; B11, Leu-Tyr; B12, Lys-Asp; C1, } \\
\text { Lys-Gly; C2, Lys-Met; C3, Met-Thr; C4, Met-Tyr; C5, Phe-Asp; C6, Phe-Glu; C7, Gln-Glu; } \\
\text { C8, Phe-Met; C9, Phe-Tyr; C10, Phe-Val; C11, Pro-Arg; C12, Pro-Asn; D1, Pro-Glu; D2, } \\
\text { Pro-Ile; D3, Pro-Lys; D4, Pro-Ser; D5, Pro-Trp; D6, Pro-Val; D7, Ser-Asn; D8, Ser-Asp; } \\
\text { D9, Ser-GIn; D10, Ser-Glu; D11, Thr-Asp; D12, Thr-Gln; E1, Thr-Phe; E2, Thr-Ser; E3, } \\
\text { Trp-Val; E4, Tyr-lle; E5, Tyr-Val; E6, Val-Ala; E7, Val-Gln; E8, Val-Glu; E9, Val-Lys; E10, } \\
\text { Val-Met; E11, Val-Phe; E12, Val-Pro; F1, Val-Ser; F2, ß-Ala-Ala; F3, ß-Ala-Gly; F4, ß-Ala- } \\
\text { His; F5, Met- ß-Ala; F6, ß-Ala-Phe; F7, D-Ala-D-Ala; F8, D-Ala-Gly; F9, D-Ala-Leu; F10, } \\
\text { D-Leu-D-Leu; F11, D-Leu-Gly; F12, D-Leu-Tyr; G1, Y-Glu-Gly; G2, Y-D-Glu-Gly; G3, } \\
\text { Gly-D-Ala; G4, Gly-D-Asp; G5, Gly-D-Ser; G6, Gly-D-Thr; G7, Gly-D-Val; G8, Leu-ß-Ala; } \\
\text { G9, Leu-D-Leu; G10, Phe-ß-Ala; G11, Ala-Ala-Ala; G12, D-Ala-Gly-Gly; H1, Gly-Gly-Ala; } \\
\text { H2, Gly-Gly-D-Leu; H3, Gly-Gly-Gly; H4, Gly-Gly-Ile; H5, Gly-Gly-Leu; H6, Gly-Gly-Phe; } \\
\text { H7, Val-Tyr-Val; H8, Gly-Phe-Phe; H9, Leu-Gly-Gly; H10, Leu-Leu-Leu; H11, Phe-Gly- } \\
\text { Gly; H12, Tyr-Gly-Gly. }\end{array}$ \\
\hline PM9 - Osmolytes & 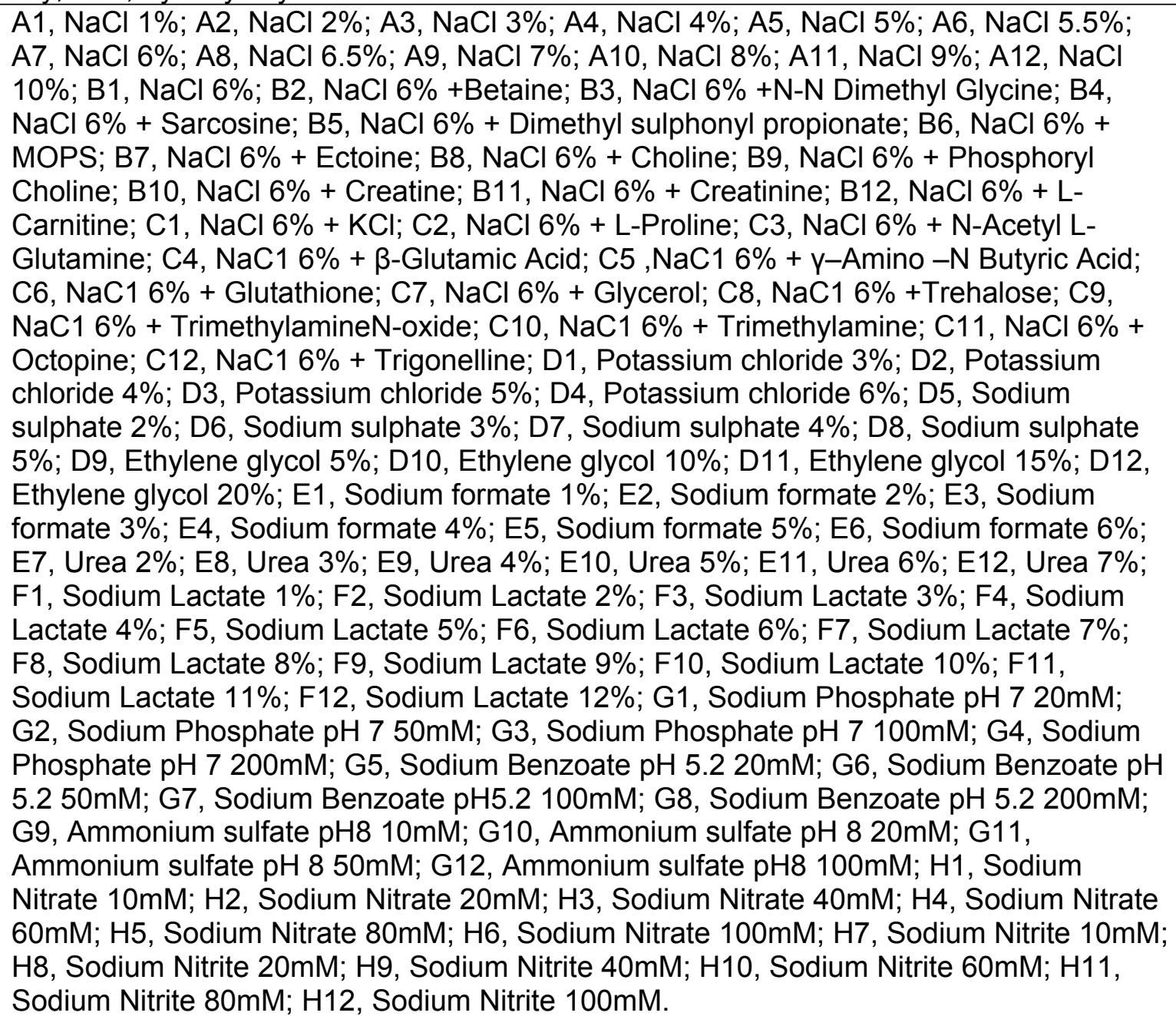 \\
\hline
\end{tabular}


$\mathrm{PM} 10-\mathrm{pH}$

PM11C - chemical
$\mathrm{A} 1, \mathrm{pH} 3.5 ; \mathrm{A} 2, \mathrm{pH} 4 ; \mathrm{A} 3, \mathrm{pH}$ 4.5; $\mathrm{A} 4, \mathrm{pH}$ 5; $\mathrm{A} 5, \mathrm{pH}$ 5.5; $\mathrm{A} 6, \mathrm{pH}$ 6; $\mathrm{A} 7, \mathrm{pH} 7 ; \mathrm{A} 8, \mathrm{pH}$ 8; $\mathrm{A}$, pH 8.5; A10, pH 9; A11, pH 9.5; A12, pH 10; B1, pH 4.5; B2, pH $4.5+$ L-Alanine; B3, pH 4.5 + L-Arginine; B4, pH $4.5+$ L-Asparagine; B5, pH $4.5+$ L-Aspartic Acid; B6, pH $4.5+$ L-Glutamic Acid; B7, pH 4.5 + L-Glutamine; B8, pH 4.5 + Glycine; B9, pH 4.5 + LHistidine; B10, pH 4.5 + L-Isoleucine; B11, pH 4.5 + L-Leucine; B12, pH 4.5 + L-Lysine; $\mathrm{C} 1, \mathrm{pH} 4.5+\mathrm{L}-$ Methionine; $\mathrm{C} 2, \mathrm{pH} 4.5+$ L-Phenylalanine; $\mathrm{C} 3, \mathrm{pH} 4.5+$ L-Proline; $\mathrm{C} 4, \mathrm{pH}$ 4.5 + L-Serine; C5, pH 4.5 + L-Threonine; C6, pH 4.5 + L-Tryptophan; C7, pH 4.5 + LCitrulline; C8, pH $4.5+$ L-Valine; C9, pH $4.5+$ HydroxyL-Proline; C10, pH $4.5+\mathrm{L}-$ Ornithine; C11, pH $4.5+$ L-Homoarginine; C12, pH $4.5+$ L-Homoserine; D-1, pH $4.5+$ Anthranilic Acid; D2, pH $4.5+$ L-Norleucine; D3, pH $4.5+$ L-Norvaline; D4, pH $4.5+\alpha-$ Amino-N Butyric Acid; D5, pH 4.5 + p-Amino Benzoic Acid; D6, pH $4.5+$ L-Cysteic Acid; D7, pH $4.5+$ D-Lysine; D8, pH $4.5+5$-Hydroxy Lysine; D9, pH $4.5+5$-Hydroxy Tryptophan; D10, pH 4.5 + D, L-Diamino pimelic Acid; D11, pH 4.5 + Trimethylamine Noxide; D12, pH 4.5 + Urea; E1, pH 9.5; E2, pH 9.5 + L-Alanine; E3, pH 9.5 + L-Arginine; E4, pH $9.5+$ L-Asparagine; E5, pH 9.5 + L-Aspartic Acid; E6, pH 9.5 + L-Glutamic Acid; E7, pH 9.5 + L-Glutamine; E8, pH 9.5 + Glycine; E9, pH 9.5 + L-Histidine; E10, pH 9.5 + L-Isoleucine; E11, pH 9.5 + L-Leucine; E12, pH 9.5 + L-Lysine; F1, pH 9.5 + L-

Methionine; F2, pH 9.5 + L-Phenylalanine; F3, pH 9.5 + L-Proline; F4, pH 9.5 + L-Serine; F5, pH 9.5 + L-Threonine; F6, pH $9.5+$ L-Tryptophan; F7, pH $9.5+$ L-Tyrosine; F8, pH $9.5+$ L-Valine; F9, pH 9.5 + Hydroxy L-Proline; F10, pH 9.5 + L-Ornithine; F11, pH $9.5+$ L-Homoarginine; F12, pH 9.5 + L-Homoserine; G1, pH 9.5 + Anthranilic acid; G2, pH 9.5 + L-Norleucine; G3, pH 9.5 + L-Norvaline; G4, pH 9.5 + Agmatine; G5, pH 9.5 + Cadaverine; G6, pH 9.5 + Putrescine; G7, pH $9.5+$ Histamine; G8, pH $9.5+$ Phenylethylamine; G9, pH 9.5 + Tyramine; G10, pH 9.5 + Creatine; G11, pH 9.5 + Trimethylamine N-oxide; G12, pH 9.5 + Urea; H1, X-Caprylate; H2, X-a-DGlucoside; H3, X- $\beta$-DGlucoside; H4, X- $\alpha$-DGalactoside; H5, X- $\beta$-DGalactoside; H6, X- $\alpha$ - DGlucuronide; H7, X- $\beta$ - DGlucuronide; H8, X- $\beta$-DGlucosaminide; H9, X- $\beta$-DGalactosaminide; H10, X- $\alpha$ DMannoside; H11, X-PO4; H12, X-SO4.

A1, Amikacin (1); A2, Amikacin (2); A3, Amikacin (3); A4, Amikacin (4); A5, Chlortetracycline (1); A6, Chlortetracycline (2) ;A7, Chlortetracycline (3); A8, Chlortetracycline (4); A9, Lincomycin (1); A10, Lincomycin (2); A11, Lincomycin (3); A12, Lincomycin (4); B1, Amoxicillin (1); B2, Amoxicillin (2); B3, Amoxicillin (3); B4, Amoxicillin (4); B5, Cloxacillin (1); B6, Cloxacillin (2); B7, Cloxacillin (3); B8, Cloxacillin (4); B9, Lomefloxacin (1); B10, Lomefloxacin (2); B11, Lomefloxacin (3); B12, Lomefloxacin (4); C1, Bleomycin (1); C2, Bleomycin (2); C3, Bleomycin (3); C4, Bleomycin (4); C5, Colistin (1); C6, Colistin (2); C7, Colistin (3); C8, Colistin (4); C9, Minocycline (1); C10, Minocycline (2); C11, Minocycline (3); C12, Minocycline (4); D1, Capreomycin (1); D2, Capreomycin (2); D3, Capreomycin (3); D4, Capreomycin (4); D5, Demeclocycline (1); D6, Demeclocycline (2); D7, Demeclocycline (3); D8, Demeclocycline (4); D9, Nafcillin (1); D10, Nafcillin (2); D11, Nafcillin (3); D12, Nafcillin (4); E1, Cefazolin (1); E2, Cefazolin (2); E3, Cefazolin (3); E4, Cefazolin (4); E5, Enoxacin (1); E6, Enoxacin (2); E7, Enoxacin (3); E8, Enoxacin (4); E9, Nalidixic acid (1); E10, Nalidixic acid (2); E11, Nalidixic acid (3); E12, Nalidixic acid (4); F1, Chloramphenicol (1); F2, Chloramphenicol (2); F3, Chloramphenicol (3); F4, Chloramphenicol (4); F5, Erythromycin (1); F6, Erythromycin (2); F7, Erythromycin (3); F8, Erythromycin (4); F9, Neomycin (1); F10, Neomycin (2); F11, Neomycin (3); F12, Neomycin (4); G1, Ceftriaxone (1); G2, Ceftriaxone (2); G3, Ceftriaxone (3); G4, Ceftriaxone (4); G5, Gentamicin (1); G6, Gentamicin (2); G7, Gentamicin (3); G8, Gentamicin (4); G9, Potassium tellurite (1); G10, Potassium tellurite (2); G11, Potassium tellurite (3); G12, Potassium tellurite (4); H1, Cephalothin (1); H2, Cephalothin (2); H3, Cephalothin (3); H4, Cephalothin (4); H5, Kanamycin (1); H6, Kanamycin (2); H7, Kanamycin (3); H8, Kanamycin (4); H9, Ofloxacin (1); H10, Ofloxacin 
(2); H11, Ofloxacin (3); H12, Ofloxacin (4).

PM12B - chemical

A1, Penicillin G (1); A2, Penicillin G (2); A3, Penicillin G (3); A4, Penicillin G (4); A5,

Tetracycline (1); A6, Tetracycline (2); A7, Tetracycline (3); A8, Tetracycline (4); A9,

Carbenicillin (1); A10, Carbenicillin (2); A11, Carbenicillin (3); A12, Carbenicillin (4); B1,

Oxacillin (1); B2, Oxacillin (2); B3, Oxacillin (3); B4, Oxacillin (4); B5, Penimepicycline (1);

B6, Penimepicycline (2); B7, Penimepicycline (3); B8, Penimepicycline (4); B9, Polymyxin

B (1); B10, Polymyxin B (2); B11, Polymyxin B (3); B12, Polymyxin B (4); C1,

Paromomycin (1); C2, Paromomycin (2); C3, Paromomycin (3); C4, Paromomycin (4);

C5, Vancomycin (1); C6, Vancomycin (2); C7, Vancomycin (3); C8, Vancomycin (4); C9,

D,L-Serinehydroxamate (1); C10, D,L-Serine hydroxamate (2); C11, D, L-Serine

hydroxamate (3); C12, D,L-Serine hydroxamate (4); D1, Sisomicin (1); D2, Sisomicin (2);

D3, Sisomicin (3); D4, Sisomicin (4); D5, Sulfamethazine (1); D6, Sulfamethazine (2); D7, Sulfamethazine (3); D8, Sulfamethazine (4); D9, Novobiocin (1); D10, Novobiocin (2);

D11, Novobiocin (3); D12, Novobiocin (4); E1, 2,4-Diamino-6,7-diisopropylpteridine (1);

E2, 2,4-Diamino-6,7-diisopropylpteridine (2); E3, 2,4-Diamino-6,7-diisopropylpteridine (3);

E4, 2,4-Diamino-6,7-diisopropylpteridine (4); E5, Sulfadiazine (1); E6, Sulfadiazine (2);

E7, Sulfadiazine (3); E8, Sulfadiazine (4); E9, Benzethoniumchloride (1); E10,

Benzethoniumchloride (2); E11, Benzethoniumchloride (3); E12, Benzethoniumchloride

(4); F1, Tobramycin (1); F2, Tobramycin (2); F3, Tobramycin (3); F4, Tobramycin (4); F5,

Sulfathiazole (1); F6, Sulfathiazole (2); F7, Sulfathiazole (3); F8, Sulfathiazole (4); F9, 5-

Fluoroorotic acid (1); F10, 5-Fluoroorotic acid (2); F11, 5-Fluoroorotic acid (3); F12, 5-

Fluoroorotic acid (4); G1, Spectinomycin (1); G2, Spectinomycin (2); G3, Spectinomycin

(3); G4, Spectinomycin (4); G5, Sulfamethoxazole (1); G6, Sulfamethoxazole (2); G7,

Sulfamethoxazole (3); G8, Sulfamethoxazole (4); G9, L-Aspartic- $\beta$-hydroxamate (1); G10,

L-Aspartic- $\beta$-hydroxamate (2); G11, L-Aspartic- $\beta$-hydroxamate (3); G12, L-Aspartic- $\beta$ -

hydroxamate (4); H1, Spiramycin (1); H2, Spiramycin (2); H3, Spiramycin (3); H4,

Spiramycin (4); H5, Rifampicin (1); H6, Rifampicin (2); H7, Rifampicin (3); H8, Rifampicin

(4); H9, Dodecyltrimethyl ammonium bromide (1); H10, Dodecyltrimethyl ammonium

bromide (2); H11, Dodecyltrimethyl ammonium bromide (3); H12. Dodecyltrimethyl

ammonium bromide (4).

PM13B - chemical

A1, Ampicillin (1); A2, Ampicillin (2); A3, Ampicillin (3); A4, Ampicillin (4); A5, Dequalinium chloride (1); A6, Dequalinium chloride (2); A7, Dequalinium chloride (3); A8, Dequalinium chloride (4); A9, Nickel chloride (1); A10, Nickel chloride (2); A11, Nickel chloride (3);

A12, Nickel chloride (4); B1, Azlocillin (1); B2, Azlocillin (2); B3, Azlocillin (3); B4,

Azlocillin (4); B5, 2, 2'-Dipyridyl (1); B6, 2, 2'-Dipyridyl (2); B7, 2, 2'-Dipyridyl (3); B8, 2, 2'-

Dipyridyl (4); B9, Oxolinic acid (1); B10, Oxolinic acid (2); B11, Oxolinic acid (3); B12,

Oxolinic acid (4); C1, 6-Mercaptopurine (1); C2, 6-Mercaptopurine (2); C3, -

Mercaptopurine (3); C4, 6-Mercaptopurine (4); C5, Doxycycline (1); C6, Doxycycline (2);

C7, Doxycycline (3); C8, Doxycycline (4); C9, Potassium chromate (1); C10,

Potassium chromate (2); C11, Potassium chromate (3); C12, Potassium chromate (4);

D1, Cefuroxime (1); D2, Cefuroxime (2); D3, Cefuroxime (3); D4, Cefuroxime (4); D5, 5-

Fluorouracil (1); D6, 5-Fluorouracil (2); D7, 5-Fluorouracil (3); D8, 5-Fluorouracil (4); D9,

Rolitetracycline (1); D10, Rolitetracycline (2); D11, Rolitetracycline (3); D12,

Rolitetracycline (4); E1, Cytosine-1- $\beta D$-arabinofuranoside (1); E2, Cytosine-1- $\beta D$ -

arabinofuranoside (2); E3, Cytosine-1- $\beta D$-arabinofuranoside (3); E4, Cytosine-1- $\beta D$ -

arabinofuranoside (4); E5, Geneticin (G418) (1); E6, Geneticin (G418) (2); E7, Geneticin (G418) (3); E8, Geneticin (G418) (4); E9, Ruthenium red (1); E10, Ruthenium red (2); E11, Ruthenium red (3); E12, Ruthenium red (4); F1, Cesium chloride (1); F2, Cesium chloride (2); F3, Cesium chloride (3); F4, Cesium chloride (4); F5, Glycine (1); F6, Glycine (2); F7, Glycine (3); F8, Glycine (4); F9, Thallium (I) acetate (1); F10, Thallium (I) acetate (2); F11, Thallium (I) acetate (3); F12, Thallium (I) acetate (4); G1, Cobalt 


\begin{tabular}{|c|c|}
\hline & $\begin{array}{l}\text { chloride (1); G2, Cobalt chloride (2); G3, Cobalt chloride (3); G4, Cobalt chloride (4); G5, } \\
\text { Manganese chloride (1); G6, Manganese chloride (2); G7, Manganese chloride (3); G8, } \\
\text { Manganese chloride (4); G9, Trifluoperazine (1); G10 ,Trifluoperazine (2); G11, } \\
\text { Trifluoperazine (3); G12, Trifluoperazine (4); H1, Cupric chloride (1); H2, Cupric chloride } \\
\text { (2); H3, Cupric chloride (3); H4, Cupric chloride (4); H5, Moxalactam (1); H6, Moxalactam } \\
\text { (2); H7, Moxalactam (3); H8, Moxalactam (4); H9, Tylosin (1); H10, Tylosin (2); H11, } \\
\text { Tylosin (3); H12, Tylosin (4). }\end{array}$ \\
\hline PM14A - chemical & 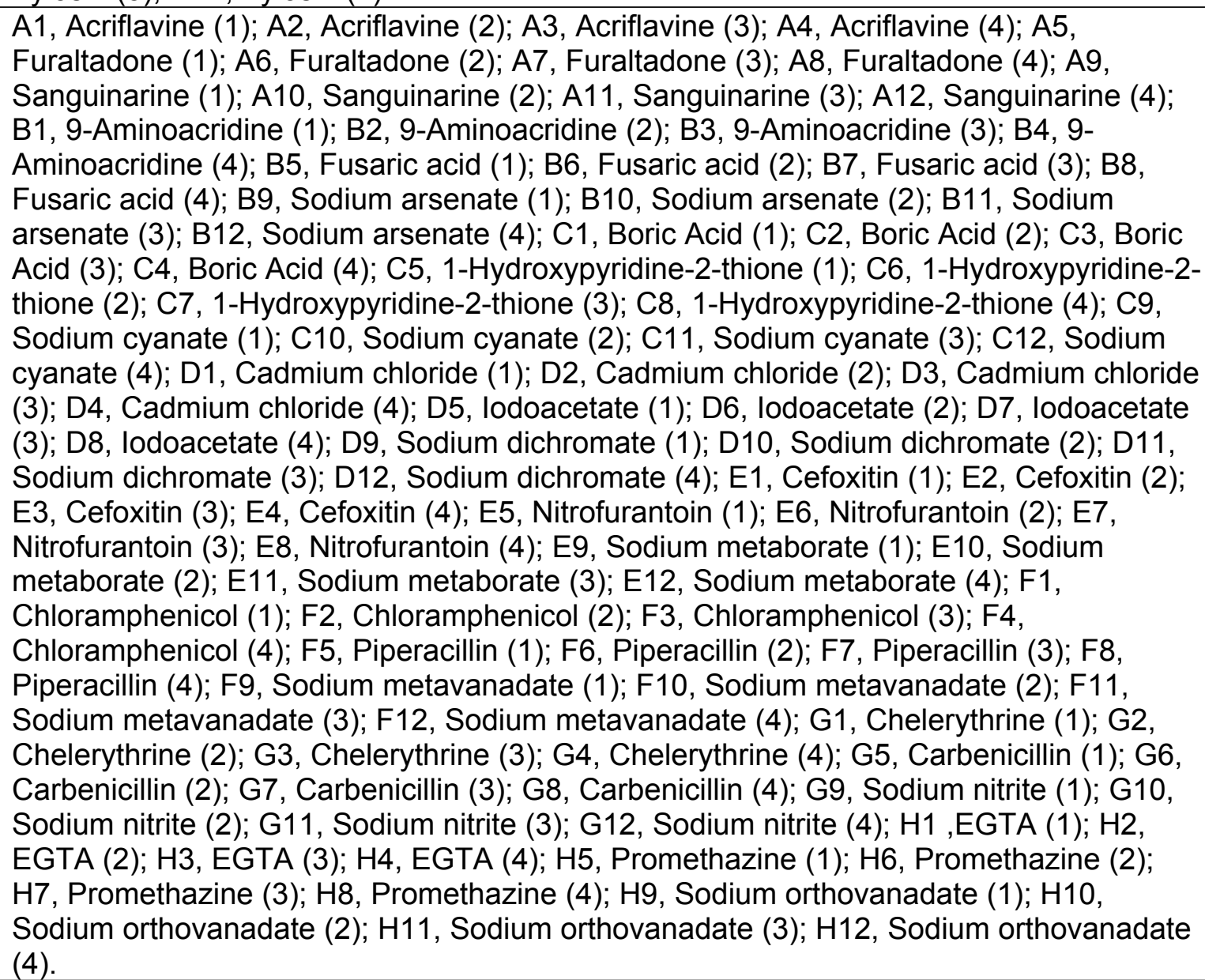 \\
\hline PM15B - chemical & $\begin{array}{l}\text { A1, Procaine (1);A2, Procaine (2); A3, Procaine (3); A4, Procaine (4); A5, Guanidine } \\
\text { hydrochloride (1); A6, Guanidine hydrochloride (2); A7, Guanidine hydrochloride (3); A8, } \\
\text { Guanidine hydrochloride (4); A9, Cefmetazole (1); A10, Cefmetazole (2); A11, } \\
\text { Cefmetazole (3); A12, Cefmetazole (4); B1, D-Cycloserine (1); B2, D-Cycloserine (2); B3, } \\
\text { D-Cycloserine (3); B4, D-Cycloserine (4); B5, EDTA (1); B6, EDTA (2); B7, EDTA (3); B8, } \\
\text { EDTA (4); B9, 5,7-Dichloro- 8-hydroxyquinaldine (1); B10, 5,7-Dichloro- 8- } \\
\text { hydroxyquinaldine (2); B11, 5,7-Dichloro- 8-hydroxyquinaldine (3); B12, 5,7-Dichloro- 8- } \\
\text { hydroxyquinaldine (4); C1, 5,7-Dichloro-8-hydroxyquinoline (1); C2, 5,7-Dichloro-8- } \\
\text { hydroxyquinoline (2); C3, 5,7-Dichloro-8-hydroxyquinoline (3); C4, 5,7-Dichloro-8- } \\
\text { hydroxyquinoline (4); C5, Fusidic acid (1); C6, Fusidic acid (2); C7, Fusidic acid (3); C8, } \\
\text { Fusidic acid (4); C9, 1,10-Phenanthroline (1); C10, 1,10-Phenanthroline (2); C11, 1,10- } \\
\text { Phenanthroline (3); C12, 1,10-Phenanthroline (4); D1, Phleomycin (1); D2, Phleomycin } \\
\text { (2); D3, Phleomycin (3); D4, Phleomycin (4); D5, Domiphen bromide (1); D6, Domiphen } \\
\text { bromide (2); D7, Domiphen bromide (3); D8, Domiphen bromide (4); D9, Nordihydroguaia } \\
\text { retic acid (1); D10, Nordihydroguaia retic acid (2); D11, Nordihydroguaia retic acid (3); } \\
\text { D12, Nordihydroguaia retic acid (4); E1, Alexidine (1); E2, Alexidine (2); E3, Alexidine (3); }\end{array}$ \\
\hline
\end{tabular}




\begin{tabular}{|c|c|}
\hline & $\begin{array}{l}\text { E4, Alexidine (4); E5, 5-Nitro-2-furaldehyde semicarbazone (1); E6, 5-Nitro-2-furaldehyde } \\
\text { semicarbazone (2); E7, 5-Nitro-2-furaldehyde semicarbazone (3); E8, 5-Nitro-2- } \\
\text { furaldehyde semicarbazone (4); E9, Methyl viologen (1); E10, Methyl viologen (2); E11, } \\
\text { Methyl viologen (3); E12, Methyl viologen (4); F1, 3, 4-Dimethoxybenzyl alcohol (1); F2, } \\
\text { 3, 4-Dimethoxybenzyl alcohol (2); F3, 3, 4-Dimethoxybenzyl alcohol (3); F4, 3, 4- } \\
\text { Dimethoxybenzyl alcohol (4); F5, Oleandomycin (1); F6, Oleandomycin (2); F7, } \\
\text { Oleandomycin (3); F8, Oleandomycin (4); F9, Puromycin (1); F10, Puromycin (2); F11, } \\
\text { Puromycin (3); F12, Puromycin (4); G1, CCCP (1); G2, CCCP (2); G3, CCCP (3); G4, } \\
\text { CCCP (4); G5, Sodium azide (1); G6, Sodium azide (2); G7, Sodium azide (3); G8, } \\
\text { Sodium azide (4); G9, Menadione (1); G10, Menadione (2); G11, Menadione (3); G12, } \\
\text { Menadione (4); H1, 2-Nitroimidazole (1); H2, 2-Nitroimidazole (2); H3, 2-Nitroimidazole } \\
\text { (3); H4, 2-Nitroimidazole (4); H5, Hydroxyurea (1); H6, Hydroxyurea (2); H7, Hydroxyurea } \\
\text { (3); H8, Hydroxyurea (4); H9, Zinc chloride (1); H10, Zinc chloride (2); H11, Zinc chloride } \\
\text { (3); H12, Zinc chloride (4). }\end{array}$ \\
\hline PM16A - chemical & 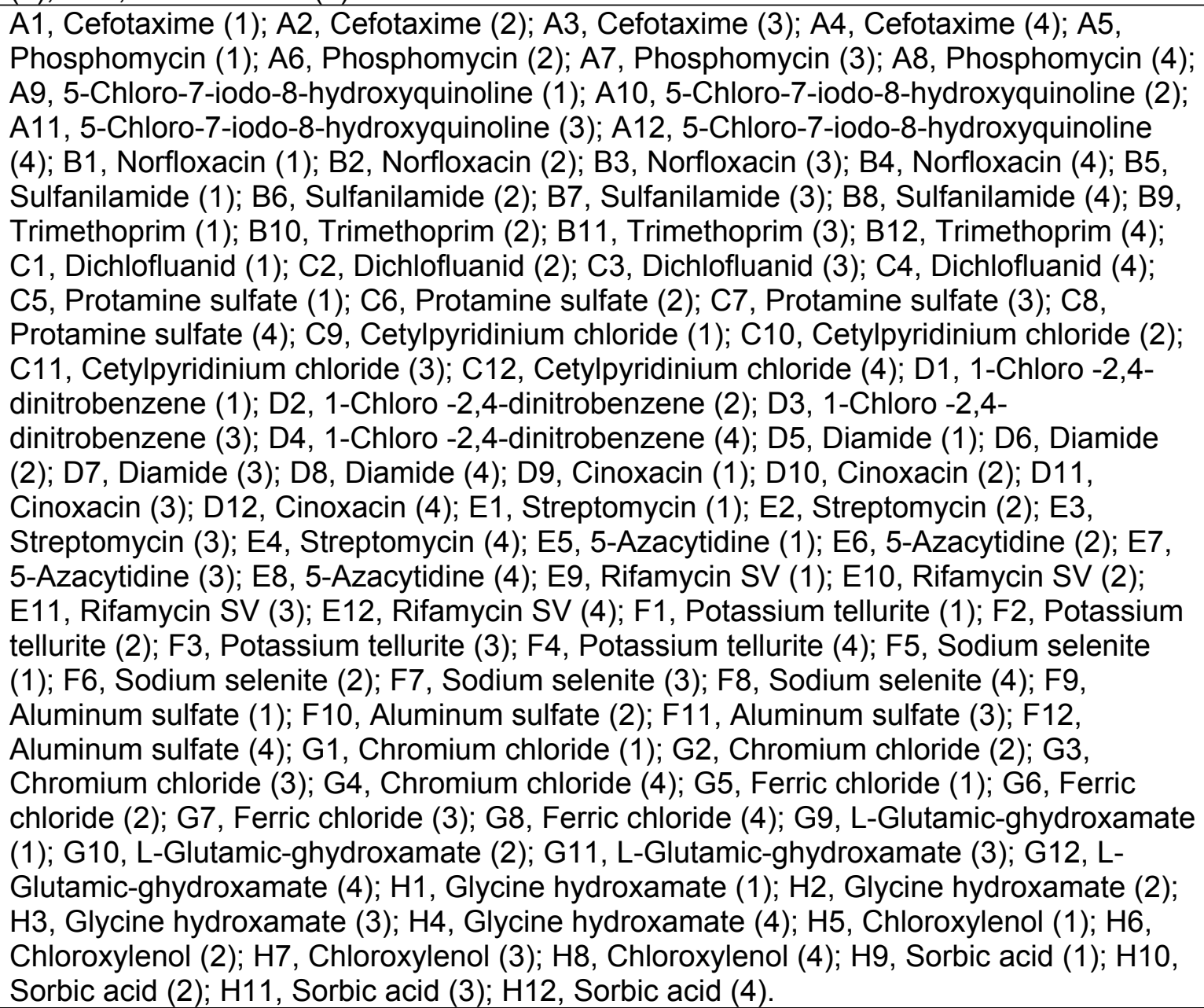 \\
\hline PM17A - chemical & $\begin{array}{l}\text { A1, D-Serine (1); A2, D-Serine (2); A3, D-Serine (3); A4, D-Serine (4); A5, } \beta \text {-ChloroL- } \\
\text { alanine hydrochloride (1); A6, } \beta \text {-ChloroL-alanine hydrochloride (2); A7, } \beta \text {-ChloroL-alanine } \\
\text { hydrochloride (3); A8, } \beta \text {-ChloroL-alanine hydrochloride (4); A9, Thiosalicylic acid (1); A10, } \\
\text { Thiosalicylic acid (2); A11, Thiosalicylic acid (3); A12, Thiosalicylic acid (4); B1, Sodium } \\
\text { salicylate (1); B2, Sodium salicylate (2); B3, Sodium salicylate (3); B4, Sodium salicylate } \\
\text { (4); B5, Hygromycin B (1); B6, Hygromycin B (2); B7, Hygromycin B (3); B8, Hygromycin } \\
\text { B (4); B9, Ethionamide (1); B10, Ethionamide (2); B11, Ethionamide (3); B12, } \\
\text { Ethionamide (4); C1, 4-Aminopyridine (1); C2, 4-Aminopyridine (2); C3, 4-Aminopyridine }\end{array}$ \\
\hline
\end{tabular}




\begin{tabular}{|c|c|}
\hline & $\begin{array}{l}\text { (3); C4, 4-Aminopyridine (4); C5, Sulfachloropyridazine (1); C6, Sulfachloropyridazine (2); } \\
\text { C7, Sulfachloropyridazine (3); C8, Sulfachloropyridazine (4); C9, Sulfamonomethoxine } \\
\text { (1); C10, Sulfamonomethoxine (2); C11, Sulfamonomethoxine (3); C12, } \\
\text { Sulfamonomethoxine (4); D1, Oxycarboxin (1); D2, Oxycarboxin (2); D3, Oxycarboxin (3); } \\
\text { D4, Oxycarboxin (4); D5, 3-Amino-1,2,4-triazole (1); D6, 3-Amino-1,2,4-triazole (2); D7, } \\
\text { 3-Amino-1,2,4-triazole (3); D8, 3-Amino-1,2,4-triazole (4); D9, Chlorpromazine (1); D10, } \\
\text { Chlorpromazine (2); D11, Chlorpromazine (3); D12, Chlorpromazine (4); E1, Niaproof (1); } \\
\text { E2, Niaproof (2); E3, Niaproof (3); E4, Niaproof (4); E5, Compound 48/80 (1); E6, } \\
\text { Compound 48/80 (2); E7, Compound 48/80 (3); E8, Compound 48/80 (4); E9, Sodium } \\
\text { tungstate (1); E10, Sodium tungstate (2); E11, Sodium tungstate (3); E12, Sodium } \\
\text { tungstate (4); F1, Lithium chloride (1); F2, Lithium chloride (2) } \\
\text { F3, Lithium chloride (3); F4, Lithium chloride (4); F5, DL-Methionine hydroxamate (1); F6, } \\
\text { DL-Methionine hydroxamate (2); F7, DL-Methionine hydroxamate (3); F8, DL-Methionine } \\
\text { hydroxamate (4); F9, Tannic acid (1); F10, Tannic acid (2); F11, Tannic acid (3); F12, } \\
\text { Tannic acid (4); G1, Chlorambucil (1); G2, Chlorambucil (2); G3, Chlorambucil (3); G4, } \\
\text { Chlorambucil (4); G5, Cefamandole nafate (1); G6, Cefamandole nafate (2); G7, } \\
\text { Cefamandole nafate (3); G8, Cefamandole nafate (4); G9, Cefoperazone (1); G10, } \\
\text { Cefoperazone (2); G11, Cefoperazone (3); G12, Cefoperazone (4); H1, Cefsulodin (1); } \\
\text { H2, Cefsulodin (2); H3, Cefsulodin (3); H4, Cefsulodin (4); H5, Caffeine (1); H6, Caffeine } \\
\text { (2); H7, Caffeine (3); H8, Caffeine (4); H9, Phenylarsine oxide (1); H10, Phenylarsine } \\
\text { oxide (2); H11, Phenylarsine oxide (3); H12, Phenylarsine oxide (4). }\end{array}$ \\
\hline PM18C - chemical & 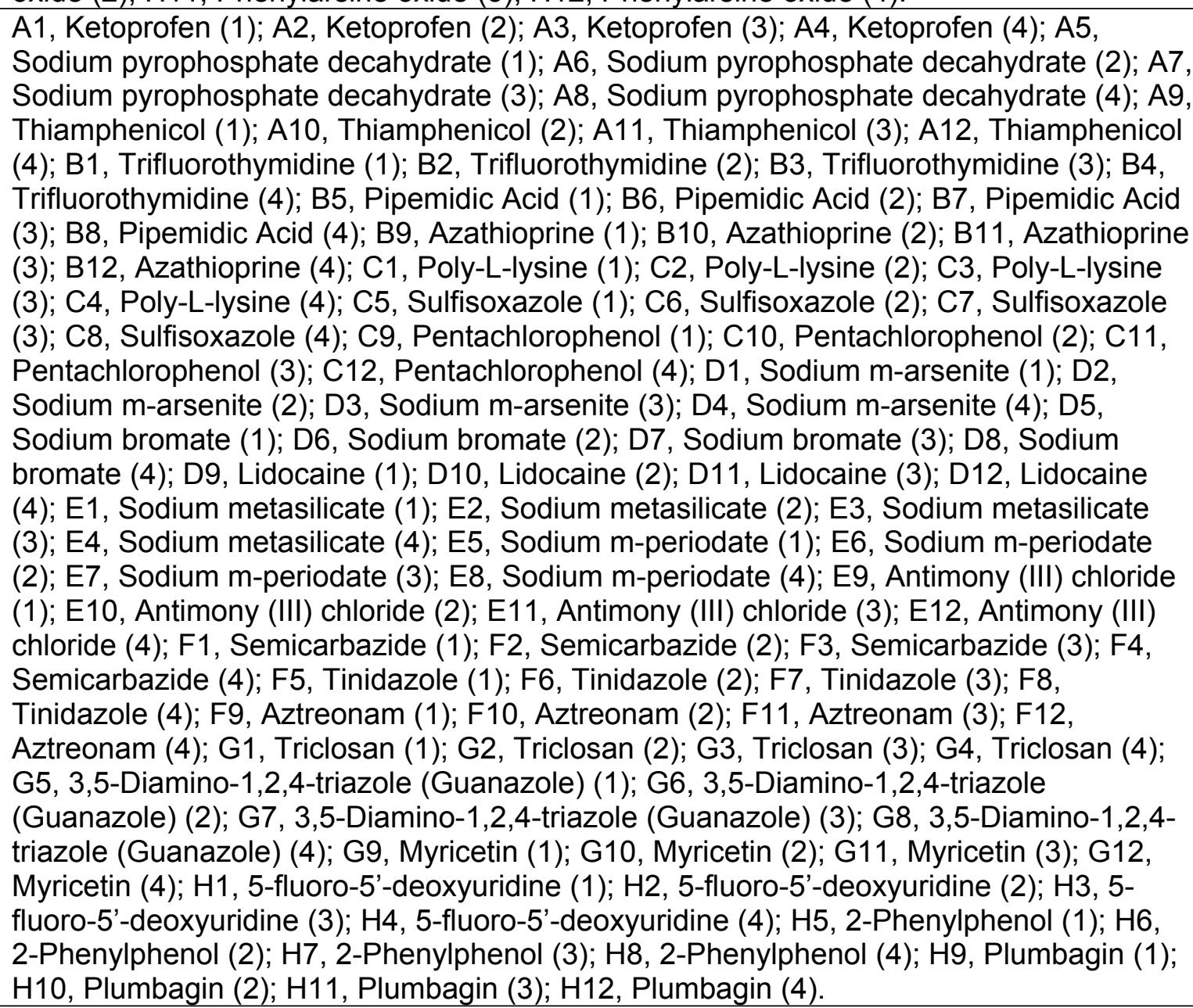 \\
\hline PM19 - chemical & A1, Josamycin (1); A2, Josamycin (2); A3, Josamycin (3); A4, Josamycin (4); A5, Gallic \\
\hline
\end{tabular}


acid (1); A6, Gallic acid (2); A7, Gallic acid (3); A8, Gallic acid (4); A9, Coumarin (1); A10, Coumarin (2); A11, Coumarin (3); A12, Coumarin (4); B1, Methyltrioctylammonium chloride (1); B2, Methyltrioctylammonium chloride (2); B3, Methyltrioctylammonium chloride (3); B4, Methyltrioctylammonium chloride (4); B5, Harmane (1); B6, Harmane (2); B7, Harmane (3); B8, Harmane (4); B9, 2,4-Dintrophenol (1); B10, 2,4-Dintrophenol (2); B11, 2,4-Dintrophenol (3); B12, 2,4-Dintrophenol (4); C1, Chlorhexidine (1); C2, Chlorhexidine (2); C3, Chlorhexidine (3); C4, Chlorhexidine (4); C5, Umbelliferone (1); C6, Umbelliferone (2); C7, Umbelliferone (3); C8, Umbelliferone (4); C9, Cinnamic acid (1); C10, Cinnamic acid (2); C11, Cinnamic acid (3); C12, Cinnamic acid (4); D1, Disulphiram (1); D2, Disulphiram (2); D3, Disulphiram (3); D4, Disulphiram (4); D5, Iodonitro Tetrazolium Violet (1); D6, Iodonitro Tetrazolium Violet (2); D7, lodonitro Tetrazolium Violet (3); D8, lodonitro Tetrazolium Violet (4); D9, Phenylmethylsulfonylfluoride (PMSF) (1); D10, Phenyl- methylsulfonylfluoride (PMSF) (2); D11, Phenyl- methylsulfonylfluoride (PMSF) (3); D12, Phenyl- methylsulfonylfluoride (PMSF) (4); E1, FCCP (1); E2, FCCP (2); E3, FCCP (3); E4, FCCP (4); E5, D,L-Thioctic Acid (1); E6, D,L-Thioctic Acid (2); E7, D,L-Thioctic Acid (3); E8, D,L-Thioctic Acid (4); E9, Lawsone (1); E10, Lawsone (2); E11, Lawsone (3); E12, Lawsone (4); F1, Phenethicillin (1); F2, Phenethicillin (2); F3, Phenethicillin (3); F4, Phenethicillin (4); F5, Blasticidin S (1); F6, Blasticidin S (2); F7, Blasticidin S (3); F8, Blasticidin S (4); F9, Sodium caprylate (1); F10, Sodium caprylate (2); F11, Sodium caprylate (3); F12, Sodium caprylate (4); G1, Lauryl sulfobetaine (1); G2, Lauryl sulfobetaine (2); G3, Lauryl sulfobetaine (3); G4, Lauryl sulfobetaine (4); G5, Dihydrostreptomycin (1); G6, Dihydrostreptomycin (2); G7, Dihydrostreptomycin (3); G8, Dihydrostreptomycin (4); G9, Hydroxylamine (1); G10, Hydroxylamine (2); G11, Hydroxylamine (3); G12, Hydroxylamine (4); H1, Hexammine cobalt (III) chloride (1); H2, Hexammine cobalt (III) chloride (2); H3, Hexammine cobalt (III) chloride (3); H4, Hexammine cobalt (III) chloride (4); H5, Thioglycerol (1); H6, Thioglycerol (2); H7, Thioglycerol (3); H8, Thioglycerol (4); H9, Polymyxin B (1); H10, Polymyxin B (2); H11, Polymyxin B (3); H12, Polymyxin B (4).

PM20B - chemical A1, Amitriptyline (1); A2, Amitriptyline (2); A3, Amitriptyline (3) A4, Amitriptyline (4); A5, Apramycin (1); A6, Apramycin(2); A7, Apramycin (3); A8, Apramycin (4); A9, Benserazide (1); A10, Benserazide (2); A11, Benserazide (3); A12, Benserazide (4); B1, Orphenadrine (1); B2, Orphenadrine (2); B3, Orphenadrine (3); B4, Orphenadrine (4); B5, D, LPropranolol (1); B6, D,L-Propranolol (2); B7, D,L-Propranolol (3), B8, D,L-Propranolol (4); B9, Tetrazolium Violet (1); B10, Tetrazolium Violet (2); B11, Tetrazolium Violet (3); B12, Tetrazolium Violet (4); C1, Thioridazine (1); C2, Thioridazine (2); C3, Thioridazine (3); C4, Thioridazine (4); C5, Atropine (1); C6, Atropine (2); C7, Atropine (3); C8, Atropine (4); C9, Ornidazole (1); C10, Ornidazole (2); C11, Ornidazole (3); C12, Ornidazole (4); D1, Proflavine (1); D2, Proflavine (2); D3, Proflavine (3); D4, Proflavine (4); D5, Ciprofloxacin (1); D6, Ciprofloxacin (2); D7, Ciprofloxacin (3); D8, Ciprofloxacin (4); D9, 18-Crown-6 Ether (1); D10, 18-Crown-6 Ether (2); D11, 18-Crown-6 Ether (3); D12, 18-Crown-6 Ether (4); E1, Crystal violet (1); E2, Crystal violet (2); E3, Crystal violet (3); E4, Crystal violet (4); E5, Dodine (1); E6, Dodine (2); E7, Dodine (3); E8, Dodine (4); E9, Hexachlorophene (1); E10, Hexachlorophene (2); E11, Hexachlorophene (3); E12, Hexachlorophene (4); F1, 4-Hydroxycoumarin (1); F2, 4-Hydroxycoumarin (2); F3, 4-Hydroxycoumarin (3); F4, 4-Hydroxycoumarin (4); F5, Oxytetracycline (1); F6, Oxytetracycline (2); F7, Oxytetracycline (3); F8, Oxytetracycline (4); F9, Pridinol (1); F10, Pridinol (2); F11, Pridinol (3); F12, Pridinol (4); G1, Captan (1); G2, Captan (2); G3, Captan (3); G4, Captan (4); G5, 3,5-Dinitrobenzene (1); G6, 3,5-Dinitrobenzene (2); G7, 3,5Dinitrobenzene (3); G8, 3,5-Dinitrobenzene (4); G9, 8-Hydroxyquinoline (1); G10, 8Hydroxyquinoline (2); G11, 8-Hydroxyquinoline (3); G12, 8-Hydroxyquinoline (4); H1, Patulin (1); H2, Patulin (2); H3, Patulin (3); H4, Patulin (4); H5, Tolylfluanid (1); H6, 

Troleandomycin (2); H11, Troleandomycin (3); H12, Troleandomycin (4). 
727 Supplementary Table 2. Genes missing from pCROD1 of C. rodentium ICC180 728

\begin{tabular}{|c|c|c|}
\hline Gene & Location & Function \\
\hline ROD_RS25055 & $240 . .494$ & Replication regulatory protein repA2 \\
\hline$R O D \_R S 25060$ & $797 . .1654$ & Replication protein \\
\hline$R O D \_R S 25065$ & $2593 . .3246$ & Hypothetical protein \\
\hline ROD_RS25070 & $3339 . .3596$ & Antitoxin \\
\hline ROD_RS25075 & $3598 . .3930$ & Hypothetical protein \\
\hline$R O D \_R S 25080$ & $4318 . .4614$ & Transposase \\
\hline ROD_RS25085 & $5726 . .6955$ & Autotransporter strand-loop-strand \\
\hline ROD_RS25090 & $6939 . .11720$ & Autotransporter \\
\hline ROD_RS25095 & 12358..12558 & Hypothetical protein \\
\hline$R O D \_R S 25100$ & $12814 . .13043$ & Transposase \\
\hline ROD_RS25105 & $14045 . .14563$ & Fimbrial protein \\
\hline ROD_RS25110 & $14636 . .17053$ & Fimbrial protein \\
\hline ROD_RS25115 & $17046 . .17738$ & Fimbrial protein \\
\hline ROD_RS25120 & $18251 . .18820$ & Hypothetical protein \\
\hline ROD_RS25125 & $18945 . .19904$ & Hypothetical protein \\
\hline ROD_RS25130 & $20068 . .20844$ & EAL domain-containing protein \\
\hline ROD_RS25135 & $22328 . .26254$ & Autotransporter \\
\hline ROD_RS25140 & $26743 . .26993$ & Toxin HigB-2 \\
\hline ROD_RS25145 & $27079 . .27339$ & Transcriptional regulator \\
\hline ROD_RS25150 & $27957 . .30536$ & Usher protein \\
\hline$R O D \_R S 25155$ & $30578 . .31048$ & Hypothetical protein \\
\hline ROD_RS25160 & $33519 . .33941$ & Twitching motility protein PilT \\
\hline
\end{tabular}




\begin{tabular}{|c|c|c|}
\hline ROD_RS25165 & $33938 . .34168$ & Virulence factor \\
\hline ROD_RS25170 & $34837 . .35055$ & Hypothetical protein \\
\hline ROD_RS25175 & $35057 . .35362$ & Hypothetical protein \\
\hline$R O D \_R S 25180$ & $35364 . .35690$ & Hypothetical protein \\
\hline ROD_RS25185 & $35680 . .36471$ & Resolvase \\
\hline ROD_RS25190 & $36627 . .40730$ & Autotransporter \\
\hline ROD_RS25730 & $41808 . .43358$ & Hypothetical protein \\
\hline ROD_RS25205 & $43907 . .44329$ & Entry exclusion protein 2 \\
\hline ROD_RS25210 & $44567 . .45523$ & Hypothetical protein \\
\hline ROD_RS25215 & $45875 . .46504$ & Serine recombinase \\
\hline ROD_RS25220 & $46779 . .47306$ & Putative resolvase \\
\hline ROD_RS25225 & $47600 . .48241$ & Chromosome partitioning protein ParA \\
\hline ROD_RS25230 & $48333 . .48665$ & Molecular chaperone GroEL \\
\hline ROD_RS25235 & $49280 . .50002$ & DNA repair protein \\
\hline ROD_RS25240 & $50082 . .51653$ & Transposase \\
\hline ROD_RS25250 & $52020 . .52697$ & Transposase \\
\hline ROD_RS25255 & $52721 . .52750$ & Endonuclease \\
\hline ROD_RS25260 & $53458 . .54144$ & Hypothetical protein \\
\hline ROD_RS25265 & $54141 . .54449$ & Hypothetical protein \\
\hline
\end{tabular}

729

730 


\section{1}

Figure 1. Whole genome sequencing shows that the lux operon and kanamcyin resistance gene have inserted at position 5,212,273 in the chromosome of $C$. rodentium ICC180, disrupting a putative site-specific DNA recombinase.

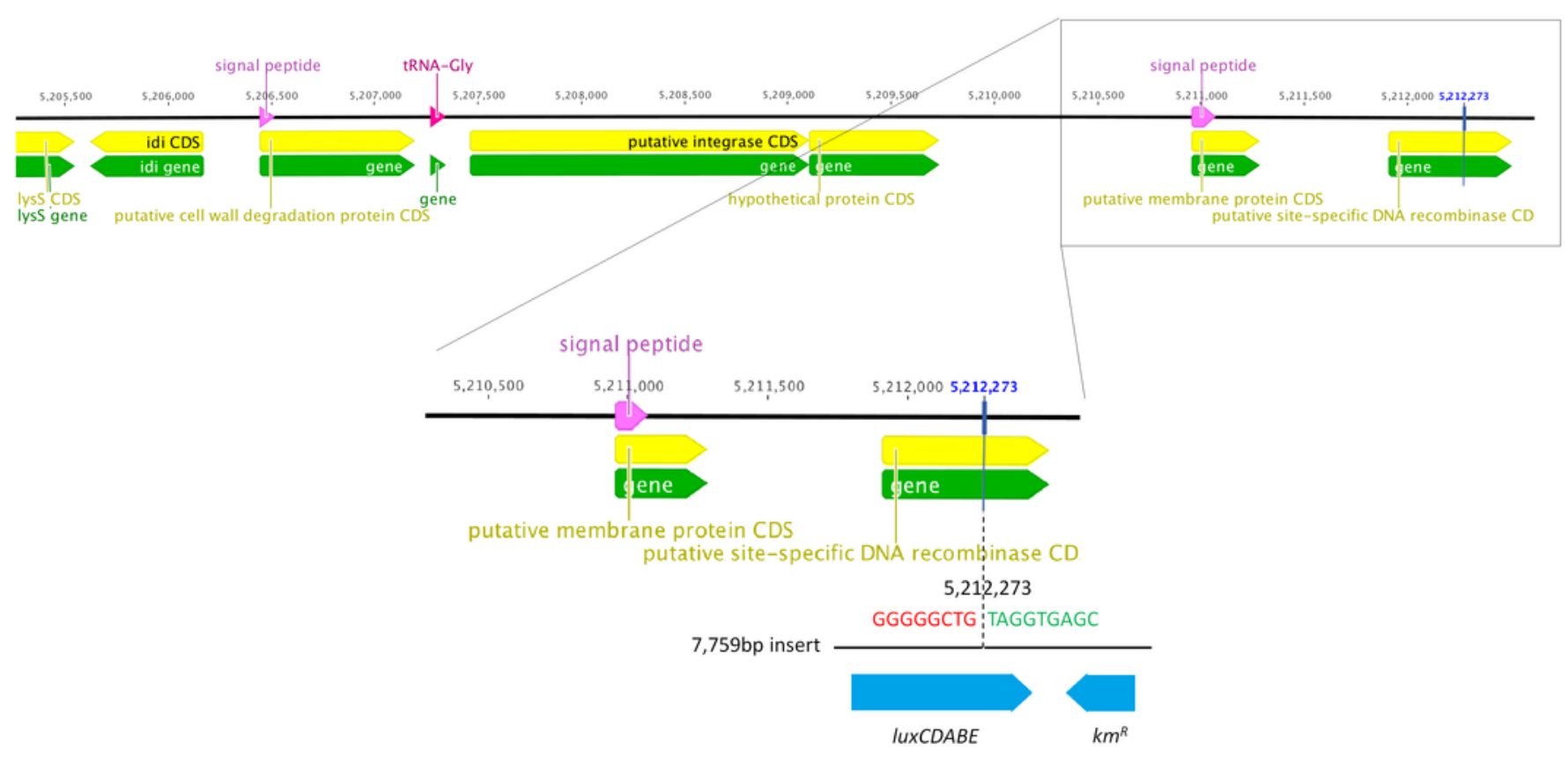




\section{2}

Figure 2. C. rodentium ICC180 is not impaired during growth in a rich laboratory medium when compared to its non-bioluminescent parent strain ICC169.

Wildtype C. rodentium ICC169 (shown as purple circles) and its bioluminescent derivative ICC180 (shown as blue triangles) were grown in LB-Lennox broth and monitored for changes in bioluminescence (given as relative light units $[R L U] \mathrm{ml}^{-1}$ ) $(A)$ and bacterial counts (given as colony forming units [CFU] $\mathrm{ml}^{-1}$ ) (B). Bacterial count data was used to calculate area under curve (AUC) values for each strain (C). Data (medians with ranges where appropriate) is presented from experiments performed on eight separate occasions.
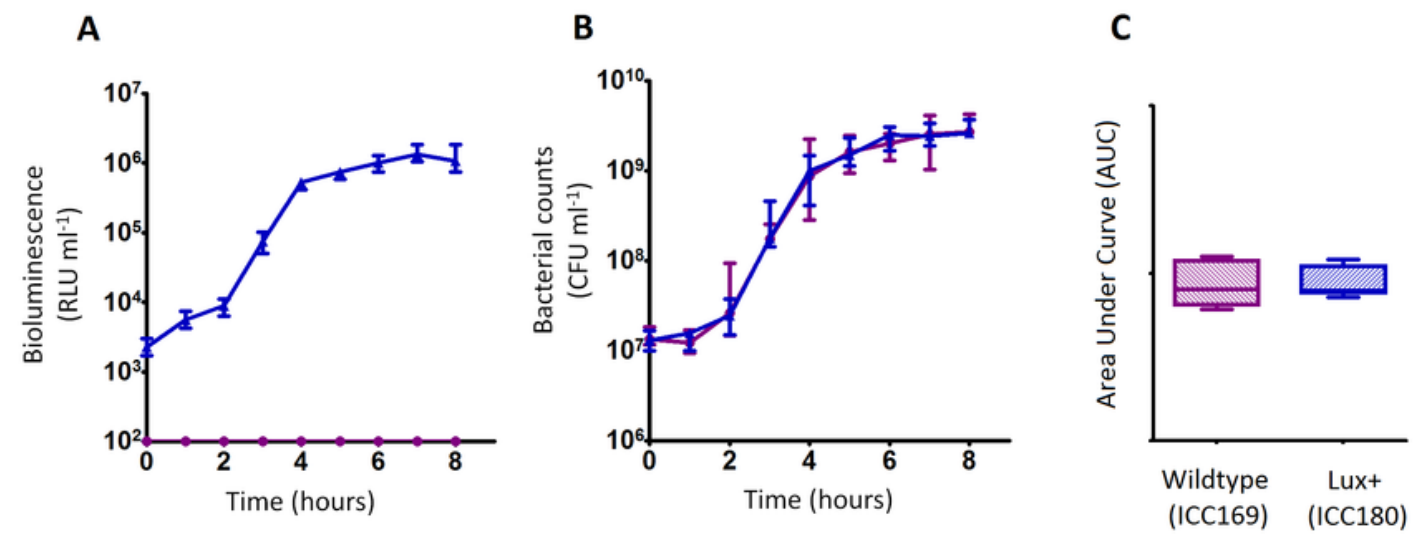


\section{3}

Figure 3. C. rodentium ICC180 is mildly impaired during growth in a defined minimal laboratory medium when compared to its non-bioluminescent parent strain ICC169.

Wildtype $C$. rodentium ICC169 (shown as purple circles) and its bioluminescent derivative ICC180 (shown as blue triangles) were grown in minimal A salts supplemented with $1 \%$ glucose and monitored for changes in bioluminescence (given as relative light units [RLU] ml$\left.{ }^{1}\right)(A)$ and bacterial counts (given as colony forming units [CFU] $\mathrm{ml}^{-1}$ ) (B). Bacterial count data was used to calculate area under curve (AUC) values for each strain, which were found to be significantly different ( $p=0.0078$; Wilcoxon Matched pairs-signed rank test) (C). Data (medians with ranges where appropriate) is presented from experiments performed on eight separate occasions.
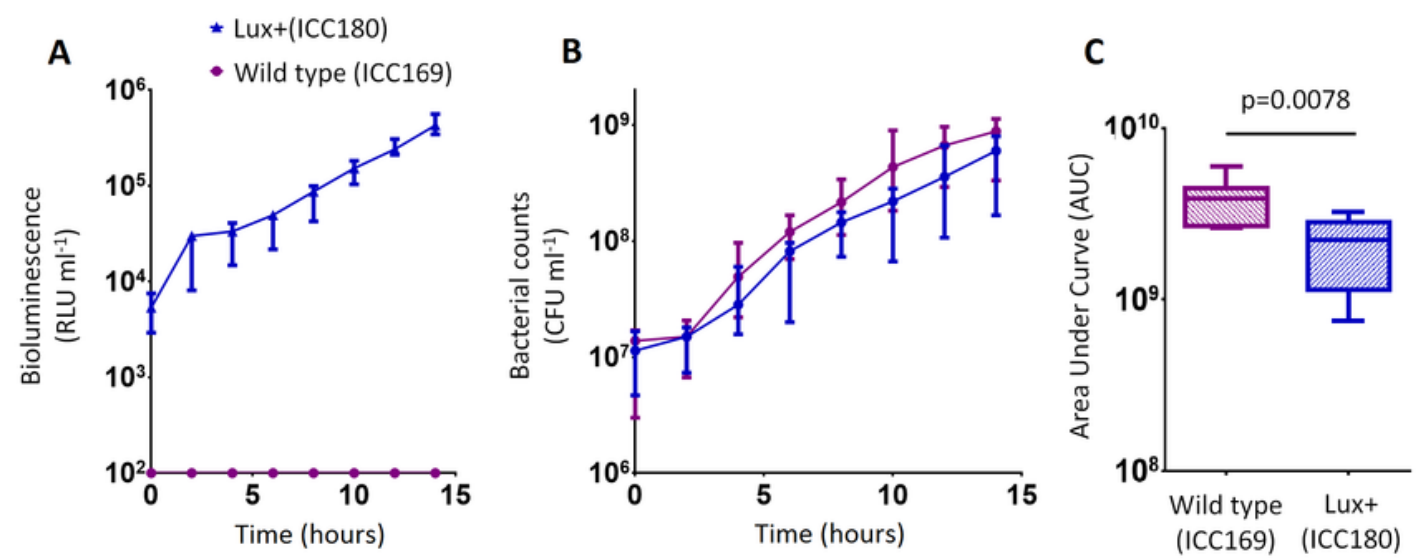


\section{4}

Figure 4. Bioluminescent $C$. rodentium ICC180 is not impaired in the Galleria mellonella infection model.

Groups of larvae $(\mathrm{n}=10)$ of the Greater Wax Moth Galleria mellonella were infected with ICC169 and ICC180 in single and 1:1 mixed infections and monitored for survival (\%) (A) and for disease symptoms using the Caterpillar Health Index (CHI), a numerical scoring system which measures degree of melanisation, silk production, motility, and mortality (given as median $\mathrm{CHI}$ values) (B). Survival curves (A) and calculated area under curve (AUC) data of $\mathrm{CHI}$ scores reveals no difference between waxworm response to infection from either strain (C). Waxworms infected with a 1:1 mix of ICC169 and ICC180 were homogenised at 24-hours, or at time of death if earlier. Actual infecting doses for each strain were determined by retrospective plating, and are indicated by *.The bacterial burden of ICC180 and ICC169 in individual caterpillars (indicated by the dotted line), was calculated after plating onto differential media and found to be significantly different $(p=0.001$; one-tailed Wilcoxon matched pairs-signed rank test) (D). Data (medians with ranges where appropriate) is presented from experiments performed on 3 separate occasions, except (A) and (D), where the results of a representative experiment are shown.
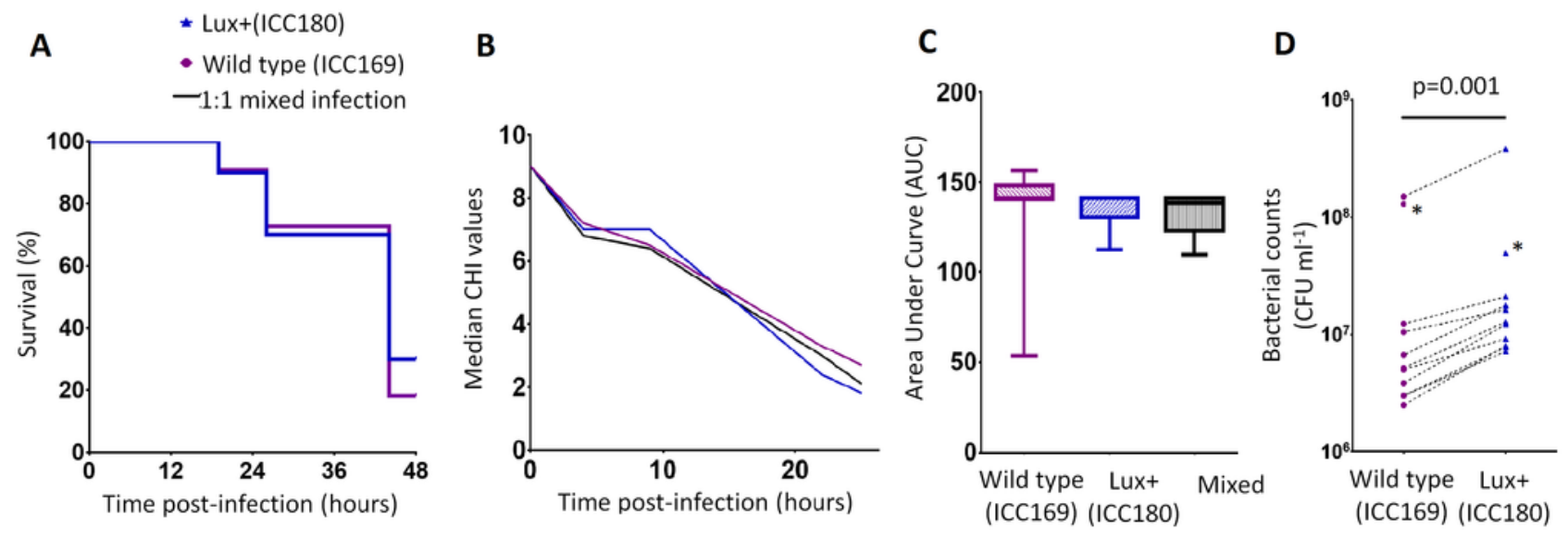


\section{5}

Figure 5. C. rodentium ICC180 is impaired during mixed, but not in single, infections in mice when compared to its non-bioluminescent parent strain ICC169.

Groups of female 6-8 week old C57BI/6 mice $(n=6)$ were orally-gavaged with $\sim 5 \times 10^{9} \mathrm{CFU}$ of wildtype $C$. rodentium ICC169 (shown as purple circles) and its bioluminescent derivative ICC180 (shown as blue triangles) in single infections (A, B) or 1:1 mixed infections (C, D) and monitored for changes in bacterial counts (given as colony forming units [CFU] $\mathrm{g}^{-1}$ stool) (A, B). Bacterial count data was used to calculate area under curve (AUC) values for each strain in single (B) and mixed (D) infections, and were found to be significantly different only for the mixed infections ( $p=0.001$; one-tailed Wilcoxon Matched pairs-signed rank test). This is reflected in the competitive indices $(\mathrm{Cl})$ calculated from the bacterial counts recovered during mixed infections, with ICC180 showing a growing competitive disadvantage from day 2 post-infection (E). Data (medians with ranges where appropriate) is presented from experiments performed on two separate occasions. 


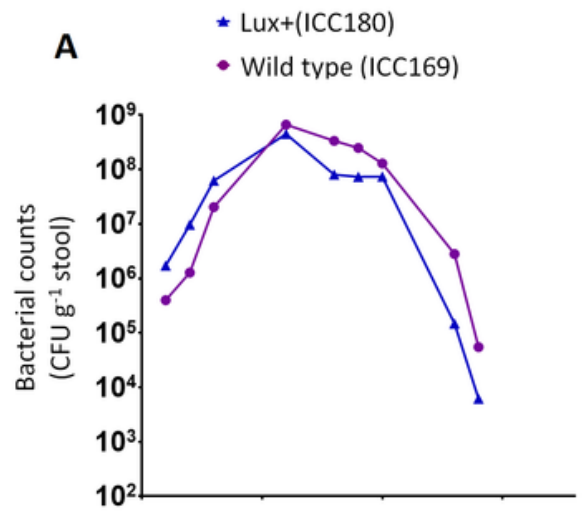

B

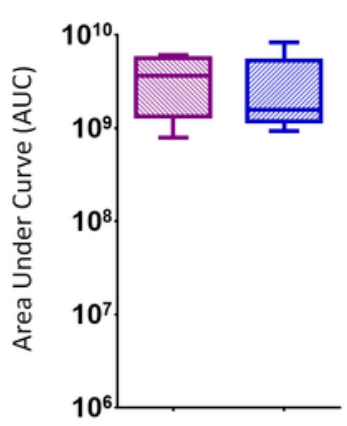

C

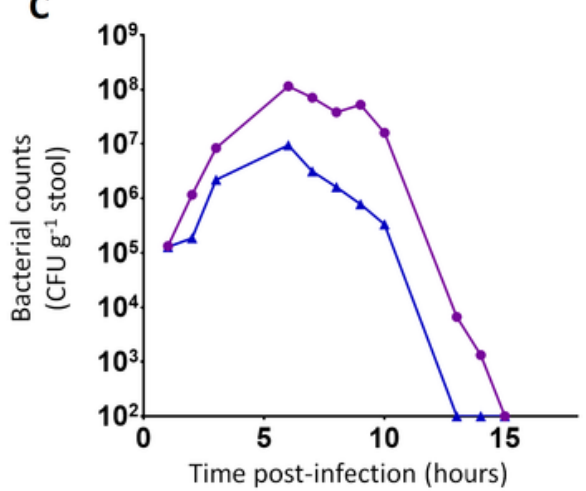

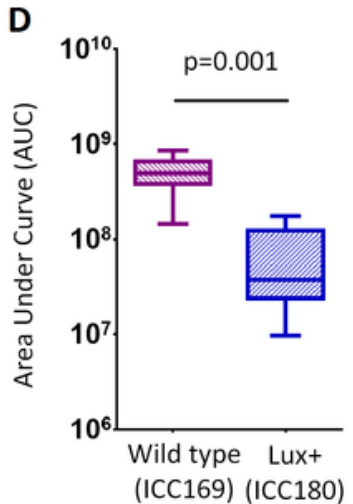

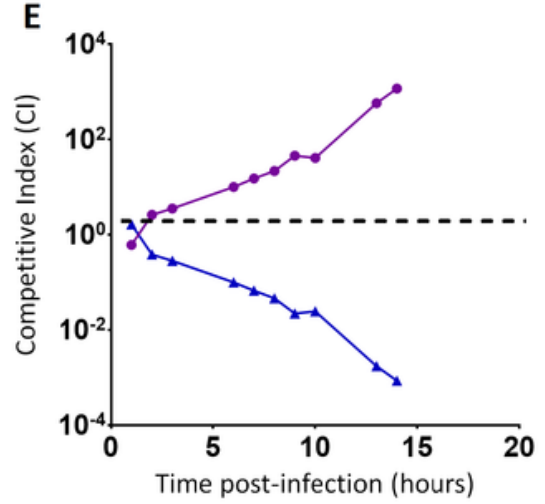


6

Figure 6. Despite having a fitness disadvantage in mixed infections of mice, ICC180 is still visible by biophotonic imaging.

Groups of female $6-8$ week old C57BI/6 mice $(n=6)$ were orally-gavaged with $\sim 5 \times 10^{9} \mathrm{CFU}$ of wildtype $C$. rodentium ICC169 and its bioluminescent derivative ICC180 in single infections or 1:1 mixed infections. Mice were anaesthetised with gaseous isoflurane and bioluminescence (given as photons second $\mathrm{d}^{-1} \mathrm{~cm}^{-2} \mathrm{sr}^{-1}$ ) from ICC180 measured using the IVIS ${ }^{\circledR}$ Kinetic camera system (Perkin Elmer). The images show changes in peak bioluminescence over time with variations in colour representing light intensity at a given location and superimposed over a grey-scale reference image (A). Red represents the most intense light emission, whereas blue corresponds to the weakest signal. Bioluminescence from the abdominal region of individual mice was quantified (as photons second ${ }^{-1}$ ) using the region of interest tool in the Living Image software program and used to calculate area under curve (AUC) values for each individual animal over the course of the infection (B). Dotted line represents background. Experiments were performed on two separate occasions. Three representative animals are shown; no light was detected from animals infected with ICC169 alone, while lower levels of light were detected from animals infected with a mix of ICC169 and ICC180.

A

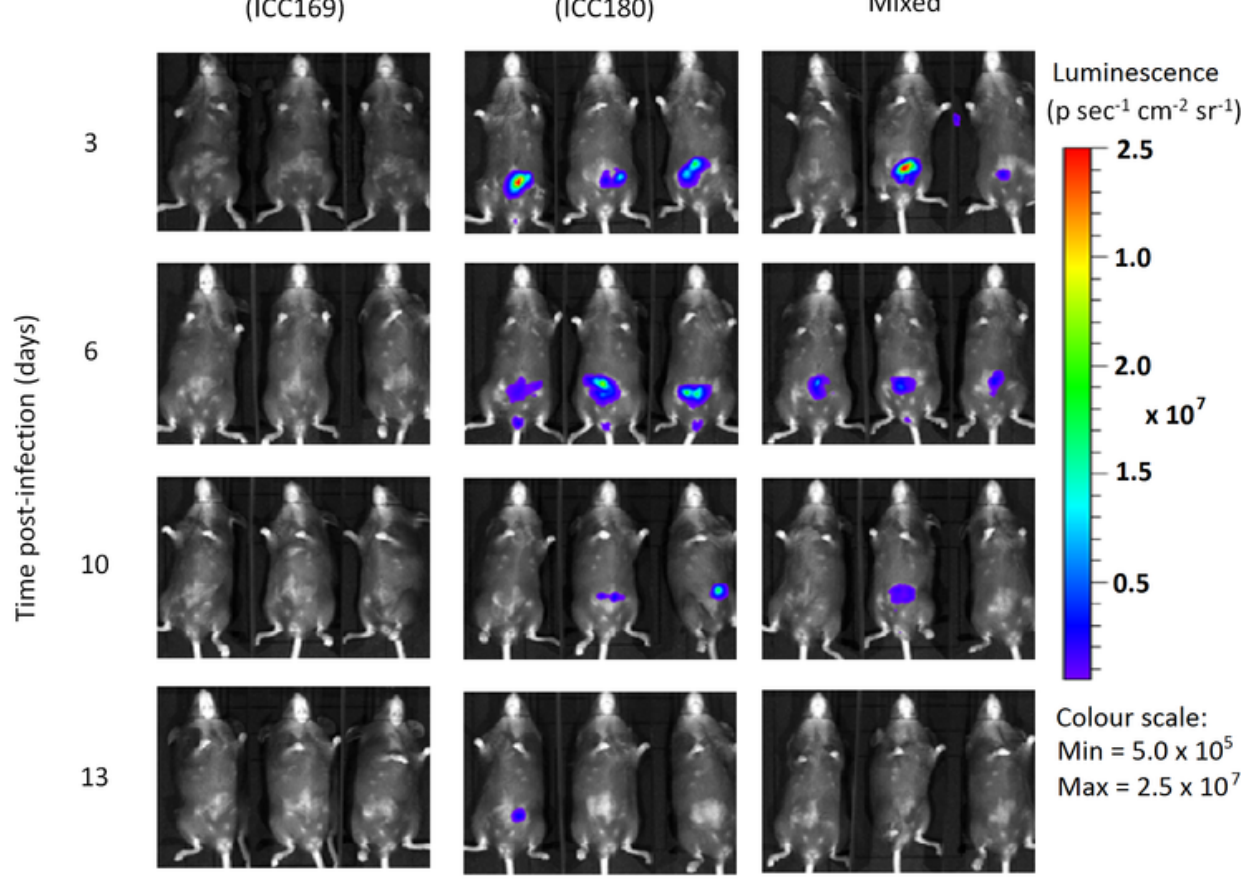

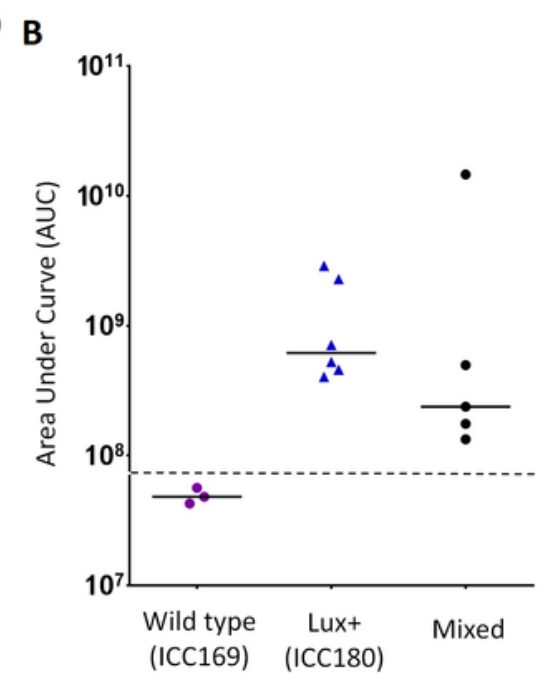

